\title{
Pobrecito hablador. Conflictos por la libre participación en una comunidad colaborativa
}

Etnografía simétrica de un weblog colectivo dedicado a la producción de noticias mediante filtrado

\section{Anonimous cowar*. Conflicts due to open participation in a colaborative comunity} Simetric ethnography of a cooperative weblog focused in the news's production through filtering

Adolfo Estalella Fernández Universitat Oberta de Catalunya / Internet Interdisciplinary Institute (IN3) [Dirección: Calle Arganda, n² 26, 7 a. 28005 Madrid] jestalellaf@uoc.edu

Adolfo Estalella es Licenciado en Física Teórica por la Universidad Complutense de Madrid (1997) y trabaja como periodista especializado en nuevas tecnologías. Realiza actualmente su tesis doctoral sobre el fenómeno de los weblogs en el Internet Interdisciplinary Institute de la Universitat Oberta de Catalunya.

\section{Resumen}

El presente estudio es el resultado de la investigación etnográfica de un weblog colaborativo. Un entorno abierto a la participación y libre expresión de cualquier usuario. La comunidad tiene como objetivo la producción de noticias significativas, para lo cual recurre a un sistema colectivo de filtrado de la información que sirve para jerarquizar las contribuciones de los usuarios. A través de este sistema de filtrado y mediante el mecanismo de registro (por el que los usuarios crean una identidad permanente) la comunidad segmenta la visibilidad y credibilidad de las informaciones según procedan de usuarios registrados o anónimos. El estudio demuestra que los procesos de selección y filtrado no sólo jerarquizan la información, sino que organizan y estructuran socialmente a la comunidad.

Palabras clave: Weblogs, Etnografía Virtual, Keywords: Weblogs, Virtual Ethnography, Virtual Comunidades Virtuales, Periodismo Participativo

\section{Abstract}

The present study is the result of an ethnographic research in a cooperative weblog, an open community where anybody can participate. The community's system of filtering thouigh which the community hierarchize users's contributions. Through this filtering system and through the registry mechanism (by which users create a permanent identity) the community segments information's visibility and credibility depending on the user's identity, whter he is a registered user or an anonomous one. The study demonstrates how the filtering processes not only hierarchize the information but organize and structre the community.

Communities, Participatoy Journalism objective of news's productio relies in a colaborative 


\section{Producción colaborativa en entornos de participación}

\section{abierta}

\subsection{Etnografía de una comunidad colaborativa}

Uno de los temas que suscitan un gran interés en los estudios del ciberespacio es cómo surge y es capaz de mantenerse la colaboración en agrupaciones y comunidades informales. Más allá del respaldo emocional característico de muchas comunidades que señala Howard Rheingold, llama poderosamente la atención la capacidad de algunas agrupaciones en Internet para producir de forma colaborativa objetos informacionales (ya sean programas de software, noticias, artículos especializados, etc)

Desde el nacimiento de Internet han existido comunidades virtuales donde la cooperación constituye un elemento esencial de su funcionamiento ${ }^{1}$. Como dice Peter Kollock, "lo maravilloso de Internet no es la existencia de tanto ruido, sino el hecho de que, al fin y al cabo, puede existir alguna colaboración significativa" (Smith y Kollock, 2003:259) pues no son pocos los dilemas que arrostra la cooperación social ${ }^{2}$.

Los conceptos acuñados para referirse a los fenómenos de colaboración en el ciberespacio han sido múltiples y han llegado desde diferentes disciplinas: inteligencia colectiva (Contreras, 2003), comunidades de open-source intelligence -inteligencia de código abierto- (Stalder y Hirsch, 2002), common-based peer production -producción compartida entre iguales- (Benkler, 2002), creación colectiva (Casacuberta, 2003), estilo bazar (Raymond, 2000), cooking-pot markets (Ghosh, 2002) o gift economies (Rheingold, 1996; Kollock, 2002). Para el caso de la comunidad y el fenómeno que nos ocupa, un weblog colaborativo, se han acuñado denominaciones propias para bautizar este tipo de producción de información como el de micro-medios o nano-medios, periodismo participativo (Bowman, Willis, 2003), open-source journalism (periodismo de código abierto), mass media colaborativos (Rafaeli, LaRose, 1993), etc.

Todas ellas hacen referencia al mismo fenómeno: una cierta forma de cooperación voluntaria, estable en el tiempo, cuyo objetivo es la producción de información y conocimiento, dentro de comunidades informales en el ciberespacio que se gestionan de forma autónoma, lo que Yochai Benkler describe como "grupos de individuos que colaboran exitosamente en grandes proyectos siguiendo un conjunto de motivaciones variadas y señales sociales, más que a partir de los precios del mercado o ordenes de gestión" (Benkler, 2002:2). El desarrollo del llamado software libre y la creación del sistema operativo GNU/Linux ${ }^{3}$ es un caso ejemplar de este tipo de colaboración ${ }^{4}$. Este modo de producción de información y conocimiento se ha extendido a otras ámbitos centrados en la elaboración de noticias de forma colaborativa como los weblogs ${ }^{5}$, el desarrollo de enciclopedias como la Wikipedia, etc ${ }^{6}$.

Uno de los elementos principales y más destacables en muchos de estos proyectos es que se desarrollan en entornos de participación abierta en los que cualquiera puede contribuir. Para lograr el 
objetivo explícito de producir información significativa dichos proyectos deben encarar el desafío de los desmanes y el desorden así como la tarea de seleccionar las contribuciones que resultan más relevantes para la comunidad.

El presente trabajo es el resultado de la observación participante de una comunidad reunida en torno a un weblog colectivo llamado Barrapunto, concebido como un entorno abierto que permite la participación de cualquier usuario. Se ha acometido usando como metodología una etnografía simétrica en la que se prescinde de las distinciones que se establecen a priori entre las categorías de lo social y lo técnico. La comunidad es descrita de esta forma como una entidad heterogénea compuesta por elementos humanos y no humanos, sociales y técnicos, todos ellos imbricados de una forma inextricable.

El estudio identifica dos elementos clave en torno a los que se organiza la comunidad. Por un lado, el ideal de participación abierta, que permite que cualquier usuario contribuya y que lo haga libremente, sin necesidad de estar registrado, y por otro, el objetivo explícito de producir información relevante y significativa para la comunidad. Para cumplir con dichos objetivos la comunidad dispone de dos mecanismos básicos: de una parte la moderación, un sistema que permite el filtrado colectivo de la información, y de otra parte la figura del pobrecito hablador, un mecanismo que permite la participación abierta y anónima de cualquiera en la comunidad.

En la primera parte del trabajo se presentan las hipótesis de partida del proyecto, algunas consideraciones metodológicas relativas a la etnografía en el ciberespacio así como una referencia a los enfoques de la Construcción Social de la Tecnología que sirven como marco teórico del estudio. La segunda sección analiza las tensiones que se generan en la comunidad debido a su planteamiento como una comunidad abierta que permite la participación de cualquier usuario anónimo. Se analiza la importante función que la identidad tiene como fuente de credibilidad y cómo la comunidad se estratifica socialmente a partir de dos funciones relacionadas con la información: credibilidad y visibilidad. La sección tercera estudia cómo el mecanismo de filtrado colectivo de la información constituye el garante de la participación abierta y cómo dicho sistema funciona como una fuente de regulación social dentro de la comunidad. La sección cuatro finaliza con una conclusión en la que se señala cómo los mecanismos destinados al filtrado de la información son los responsables de la organización social de la comunidad.

\section{Preguntas de investigación e hipótesis}

El interés básico de la investigación es describir cómo se organiza y sostiene la producción de información significativa en una comunidad colaborativa que es abierta. Una de las hipótesis de partida del estudio es que el componente tecnológico constituye un elemento fundamental en la organización de la producción de muchas de estas comunidades. El estudio tratará de determinar qué función tiene el componente tecnológico en dos aspectos que se consideran clave en el mantenimiento de comunidades de producción colaborativa: los mecanismos que animan y sostienen 
la participación en la comunidad y los que integran y hacen significativas las diferentes contribuciones de sus usuarios.

Toda comunidad abierta y basada en la colaboración voluntaria de sus miembros, como la que es objeto de este estudio, corre el peligro de fracasar si no consigue aglutinar y mantener la participación, o, en su reverso puede fracasar a causa de los desmanes provocados por trolls, la avalancha de información inútil, etc. Los entornos abiertos se enfrentan a la necesidad de motivar y sostener la participación de sus usuarios al tiempo que controlan las amenazas provenientes de la libre participación. En segundo lugar el objetivo de producir información significativa implica la necesidad de sistemas que sirvan para seleccionar la información. El propósito del estudio ha sido determinar cuáles son los mecanismos específicos que la comunidad desarrolla para responder a esas necesidades. La pregunta de investigación de la que se parte es:

\section{¿Cómo se organiza y se mantiene la producción de información en una comunidad} abierta?, afinando más y concretando para la comunidad objeto de estudio,

¿cómo gestiona y sostiene la participación abierta y voluntaria la comunidad y al mismo tiempo logra producir información significativa?

Dicha pregunta obliga a tratar de identificar los siguientes elementos: (i) los diferentes mecanismos técnicos que sostienen y animan la participación, (ii) los sistemas que mantienen la participación abierta y libre, (iii) los mecanismos destinados al filtrado de la información.

\subsection{Comunidades como ensamblajes sociotécnicos}

El estudio se apoya en dos pilares teóricos para su desarrollo: (i) la idea de que la identidad es flexible, múltiple y descentralizada, un proceso de construcción permanente ${ }^{7}$ y en (ii) los estudios sobre la Construcción Social de la Tecnología que aportan el marco teórico y el aparato conceptual necesario para realizar una etnografía simétrica.

La etnografía simétrica prescinde de lo que se consideran distinciones a priori entre lo que es social y lo que es técnico. Aplicada al estudio de una comunidad virtual, una etnografía simétrica parte de la premisa de que no es posible distinguir entre lo que es tecnológico y social, natural y artificial. Los límites entre unas categorías y otras están cada vez más borrosos. Como señala Michel Callon al hablar del principio de simetría en los estudios sociales de la ciencia, "la regla que debemos respetar es no cambiar de registro cuando nos movemos de los aspectos técnicos del problema estudiado a los sociales" (Doménech, 1998:19). Desde el punto de vista metodológico esto nos lleva a no discriminar entre el tipo de causas que explican la dinámica de la comunidad y a buscar en todos los fenómenos su origen sociotécnico, la composición indisoluble de elementos de origen humano y material, social y tecnológico, en la producción del fenómeno. El planteamiento de la comunidad como un espacio abierto, por ejemplo, se construye tanto a través del ideal de participación abierta como mediante el mecanismo de origen material del pobrecito hablador.

Diferentes autores han puesto de manifiesto la importante función de la infraestructura técnica en las comunidades en el ciberespacio (Wellman, 1999; Jones, 1998) y cómo ésta modela la interacción que 
se desarrolla en ellas (Baym, 1998). Peter Kollock y Marc Smith señala en el prólogo de la obra Comunidades en el ciberespacio cómo diferentes sistemas de comunicación (chat, BBS, MUD, etc.) dan lugar a dinámicas sociales muy diferentes.

Dichos análisis adolecen sin embargo de cierto reduccionismo tecnológico al considerar únicamente el efecto del componente técnico sobre la dinámica y la organización de la comunidad, sin tomar en cuenta el efecto en sentido contrario: el que ejerce la comunidad sobre la infraestructura técnica. En el extremo opuesto a este determinismo tecnológico se encuentran los trabajos que adolecen de un reduccionismo social que considera el componente técnico como inerte, un simple escenario donde se desarrolla la interacción social (Jones, Q., 1997).

Estos planteamientos son superados por los estudios sobre la Construcción Social de la Tecnología (CST) que han mostrado cómo "lo técnico está socialmente construido, y lo social está técnicamente construido" (Bijker, 1995:273). Los usuarios construyen el significado de las tecnologías con sus prácticas porque la tecnología está sometida a flexibilidad interpretativa, un concepto fundamental del constructivismo social (Pacganella, 1997) de la Construcción Social de la Tecnología desarrollada por Wiebe E. Bijker y a Trevor Pinch ${ }^{8}$. En su obra Of Bicycles, Bakelites and Bulbs. Towards a Theory of Sociotechnical Change, Bijker apunta el significado de la flexibilidad interpretativa:

Uno nunca debería tomar que el significado de un artefacto técnico o un sistema tecnológico reside en la misma tecnología. En su lugar, uno debe estudiar cómo las tecnologías son moldeadas y adquieren sus significados en la heterogeneidad de las interacciones sociales. Otra forma de establecer el mismo principio es usar la metáfora de la "red abierta" de la ciencia, la tecnología y la sociedad, que es un medio para recodar al investigador que no acepte de primeras la distinción entre, por ejemplo, lo técnico y lo social tal y como se presentan a sí mismos en una determinada situación. (Bijker, 1995:6)

Este planteamiento ha sido aplicado al estudio de comunidades en el ciberespacio (Hine, 2000; Aibar et al., 2000), en trabajos que muestran que "el estudio de una comunidad virtual, consecuentemente, no debería restringirse únicamente al análisis de la interacción entre los participantes humanos: ni estos son los mismos que antes de convertirse en participantes del forum [o de cualquier comunidad virtual] ni son los únicos actores en el mismo" (Aibar et alt., 2000:70). Especialmente interesante y pertinente es el estudio de Anita J. Chan sobre Slashdot (Chan, 2002), un sitio estadounidense que constituye el modelo original de la comunidad estudiada. Chan toma como marco teórico para el estudio de esta comunidad el Constructivismo Social.

Adoptar el planteamiento de la Construcción Social de la Tecnología al estudio de una comunidad en el ciberespacio tiene dos implicaciones fundamentales. Obliga a estar en guardia y a considerar permanentemente la forma como la comunidad dota de significado al componente técnico y reelabora constantemente con sus prácticas un technological frame (arquitectura técnica). En segundo lugar obliga a prescindir de las distinciones que se hacen a priori entre lo que es social y lo que es tecnológico, lo que es natural y construido dentro de la comunidad, la cual es descrita como un ensamblaje sociotécnico ${ }^{9}$ (Bijker, 1995:273-279) constituido por reunión de actores heterogéneos, humanos y no humanos, significados, prácticas, artefactos, etc.

Ambos conceptos son fundamentales en el análisis de la comunidad y merecen ser definidos con precisión, según Bijker la arquitectura técnica: 
Estructura las interacciones entre los actores de un grupo social relevante. De manera que no es una característica individual, ni una característica de los sistemas o las instituciones; los technological frames están localizados entre los actores, no en los actores, o sobre los actores. Un technological frame está construido cuando las interacciones en torno a los artefactos comienzan [...] un technological frame comprende todos los elementos que influyen en las interacciones dentro de los grupos sociales relevantes y que llevan a la atribución de significados a los artefactos tecnológicos -y así a la constitución de la tecnología. (Bijker, 1995: 123)

El ensamblaje sociotécnico es un concepto que apunta a la emergencia de una nueva categoría, lo sociotécnico, que borra las distinciones que se establecen a priori entre lo social y lo técnico. Lo sociotécnico no es simplemente la suma de las otras dos, como declara Bijker:

Lo técnico está construido socialmente, tanto como lo social está construido técnicamente. Todos los ensamblajes se mantienen unidos tanto por lo técnico como por lo social [...] lo sociotécnico no debe ser tratado simplemente como una combinación de factores sociales y técnicos. Es algo sui generis. En lugar de artefactos, nuestra nueva unidad de análisis es ahora el 'ensamblaje sociotécnico' [...] La sociedad no está determinada por la tecnología, ni la tecnología está determinada por la sociedad. Las dos emergen como dos caras de una misma moneda sociotécnica, durante el proceso de construcción de los artefactos, los hechos y los grupos sociales relevantes (Bijker, 1995:273-274)

Una comunidad en el ciberespacio es un ensamblaje sociotécnico en el que lo social y lo técnico están unidos de forma inextricable. Adoptar el planteamiento de la CST en el estudio de una comunidad en el ciberespacio implica por lo tanto una ruptura con el reduccionismo social y el reduccionismo tecnológico y significa prescindir de las distinciones que se establecen a priori entre toda una serie de categorías, como lo social y tecnológico, natural y artificial, on-line y off-line, etc, en su lugar, se usa la categoría de los socio-técnico porque resulta imposible desligar y dejar de lado lo que es "estrictamente social" de lo que es "estrictamente técnico".

\section{Etnografía en el ciberespacio e identidad del investigador}

En los últimos años la etnografía ha ampliado su campo de aplicación al estudio de las interacciones sociales en el ciberespacio, donde ha tenido que ofrecer nuevas propuestas porque "la etnografía virtual no es pues una mera adaptación de un "viejo" método a un nuevo objeto de estudio" (Ardèvol et alt., 2003:18).

Uno de los problemas básicos al acometer cualquier estudio etnográfico es la ausencia de un corpus metodológico establecido, unas reglas de aplicación que guíen con precisión la actividad del investigador (Contreras, 2003:55), que se ve obligado a improvisar a menudo y construir su metodología de forma contextual a medida que avanza en su trabajo, manteniendo una permanente actitud reflexiva.

La mayor parte de los estudios sobre comunidades en el ciberespacio mantienen la distinción entre las categorías de lo social y lo tecnológico, lo natural y lo artificial, la sociedad y la técnica, y las trasladan al ciberespacio generando nuevas dicotomías: auténtico (en el espacio off-line, en la 
identidad física) y simulado (en el ciberespacio, en la identidad digital), real y virtual, etc. Esa distinción, que privilegia y asume como más genuina la interacción cara a cara, tiende de forma injustificada un manto de sospecha sobre la interacción en los espacios digitales y sobre las identidades que se construyen en ellos. La autenticidad de las interacciones y de las identidades debe tomarse como elementos que se definen contextualmente por los propios protagonistas (Hine, 2000:49). La etnografía simétrica, hundiendo sus planteamientos en el enfoque de la CST, supera estas dicotomías.

\section{La construcción de la identidad del investigador}

La mayor parte de las etnografías implican un viaje de transición hacia el campo de estudio. Los lugares del ciberespacio están normalmente al alcance de cualquiera que tenga delante un ordenador interconectado. Esta facilidad para arribar no significa sin embargo que se pueda acceder a ellos con la misma sencillez.

La etnografía implica la participación directa del investigador. No basta con la observación de lo que ocurre, es necesario estar en la comunidad y ser uno más. Pero esto no es sencillo ya que requiere un notable esfuerzo para desarrollar una identidad propia ${ }^{10}$ dentro de la comunidad.

Construir la identidad es un proceso largo que se desarrolla durante la misma observación participante, en la interacción con los otros. En los espacios digitales "el yo es múltiple, fluido y constituido en interacción con conexiones en una máquina" (Turkle, 1997:23). Un aspecto muy importante de la concepción de la identidad de Sherry Turkle es su idea de que "construimos a nuestras tecnologías y nuestras tecnologías nos construyen a nosotros en nuestros tiempos" (Turkle, 1997:60). La psicóloga estadounidense deshace en el ámbito de la identidad la distinción a priori entre las categorías de lo social y lo tecnológico de la que hemos prescindido y apunta al papel fundamental de la tecnología en la construcción de nuestras identidades. Vuelve a reafirmarse de esta manera la idea de que no se puede privilegiar el espacio y la interacción en el entorno no digital frente al ciberespacio, ni tampoco la identidad del primero frente a la construida en el segundo.

\section{La recogida de datos}

Los datos para el trabajo se recogieron a lo largo de cinco meses (entre abril y agosto de 2004) y proceden de varios espacios: las bitácoras, la portada, la lista de editores y las entrevistas personales. Las bitácoras (figura 7$)^{11}$ han supuesto la fuente de información fundamental junto con las entrevistas personales. La portada es uno los principales espacios de Barrapunto, donde se publican diariamente media decena de noticias, con un número de comentarios variable (desde decenas a centenares) (figura 1).

La lista de coordinación de los editores es usada para discutir los asuntos de la gestión diaria del sitio. Los datos recogidos en ella me han ayudado a entender el modelo de gestión adoptado por ellos. Las entrevistas personales se realizaron a cuatro editores y cuatro usuarios. En cada categoría tres de las 
entrevistas se hicieron por teléfono y una de ellas cara a cara. La duración aproximada fue de una hora en cada caso, se grabaron y se transcribieron íntegramente.

Se eligieron los usuarios siguiendo dos criterios: alta participación y variedad en sus perfiles de participación. Para realizar la selección se usaron varios indicadores como las bitácoras con más entradas publicadas, los usuarios que tienen más amigos, los que más noticias han enviado y el historial de cada usuario que ofrece detallada información sobre su participación.

\section{Tensión entre credibilidad y libre expresión en un entorno abierto}

\subsection{Una comunidad para el consumo y la producción de información}

Los usuarios de Barrapunto reconocen que el sitio tiene un doble enfoque: como un espacio de información con las últimas noticias y un lugar donde debatir y aportar información. En esto coinciden musg1, agente_naranja, Aloriel o Yuyah, los usuarios de Barrapunto entrevistados. Yuyah, por ejemplo, un programador de 26 años con quien pude reunirme cara a cara, confiesa acudir obsesivamente a Barrapunto a diario y describe así su actividad en el sitio:

Entro para leer, y me suelo leer las noticias de la portada, y si hay alguna que me interesa pues me leo todos los comentarios, todos, todos, incluso hay noticias que las vuelvo a visitar para ver todos los comentarios, y luego pues las bitácoras, y ha habido momentos pues que no ha habido mucho movimiento pues también las noticias pendientes de envío, también, todas, entrar entro mucho, sobre todo si tengo tiempo y no tengo cosas que hacer en el trabajo, entro bastante, 20 o 30 veces, si no tengo nada que hacer. (E. P., Yuyah, 1) ${ }^{12}$

Barrapunto es una especie de portal de noticias relacionadas con la tecnología y el software libre. En enero de 2005 tenía unos 15.000 usuarios registrados, aunque no es necesario registrarse para participar. El sitio se mantiene a través de las contribuciones de sus usuarios. Cualquiera (registrado o no) puede mandar una noticia que pasa a una lista de envíos a la espera de que algún editor la considere de interés y la publique en la portada. El resto de usuarios puede añadir después comentarios a la noticia, que suelen ser textos de corta extensión (unas 100 palabras), de estilo informal que conmina a los demás a la participación (“¿y tú qué opinas?”, es un cierre habitual para las noticias). Un ejemplo de noticia:

hewop nos cuenta: «La pregunta es muy simple. ¿Qué navegador usais para ver esta web? He encontrado problemas con ciertos navegadores para poder ver /. De todas ellas la más reciente y grave es a raíz del "cierre" de la web en protesta contra las patentes de software, ya que ni Firebird ni Firefox me dejan acceder. EI IE, el NS y el Opera la muestran correctamente. ¿Habéis tenido problemas similares? ¿Que navegador usais?» Hmm. Mi Galeon no parece tener problemas... Pero en cualquier caso, interesante lo de saber qué se usa por ahí fuera. Aunque yo añadiría: ¿por qué es eso lo que usas? 
La portada es el espacio central de Barrapunto, donde se publican las noticias, en las cuales los comentarios constituyen un componente fundamental, y así lo reconocen los mismos editores, sin los comentarios Barrapunto "no vale para nada", dice fernand0, profesor universitario y uno de los editores entrevistados ${ }^{13}$.

Cualquiera puede comentar en Barrapunto, que se presenta como un espacio "abierto" a todos, sean expertos o no, aunque desconozcan la normas implícitas del sitio o no se encuentren registrados. Esto implica exponerse a desmanes y comportamientos abusivos o anómalos, pero este planteamiento de participación abierta es una máxima, como comenta en la entrevista telefónica rvr, uno de los editores más activos del sitio:

la política de Barrapunto de siempre ha sido libertad total y absoluta para opinar en lo que los usuarios quieran, aún a costa de que esa libertad se entienda como libertinaje y que haya usuarios que abusen de su libertad para opinar, pero esa es la política de Barrapunto, esté o no de acuerdo con ella. (E. P., Aloriel, 4)

Pero no todas las opiniones son igual de valiosas, y por eso no todos los usuarios tienen la misma visibilidad dentro de Barrapunto. En las FAQ (preguntas más frecuentes) sobre la moderación, como se llama al sistema de filtrado de información, se deja muy claro que "no todos los comentarios son interesantes. De hecho, algunos son terribles mientras que otros son casi auténticas joyas" ${ }^{\prime 14}$. Junto con el ideal de participación abierta la comunidad mantiene por lo tanto el objetivo de seleccionar la información que se considera más significativa.

Mantener Barrapunto como un espacio abierto a la participación de cualquiera (esté registrado o no) y permitir la completa libertad de expresión (a través del anonimato), junto con el objetivo de producir (a través de mecanismos de filtrado) las informaciones más significativas para la comunidad son dos objetivos fundamentales que van a modelar poderosamente la dinámica de Barrapunto.

Para realizar el filtrado se usa como principal mecanismo la moderación y la identidad, y para permitir la participación abierta existe la figura del pobrecito hablador. A través de la moderación y la identidad la información que proporcionan los usuarios queda segmentada de acuerdo a dos variables, el grado de visibilidad de la información y su credibilidad.

Esta segmentación de la información tiene un importante efecto sobre la organización social de Barrapunto, puesto que el sistema de estratificación social deriva de las propiedades de la información (visibilidad y la credibilidad) que suministran los usuarios.

\subsection{Identidad, fuente de credibilidad}

Como ocurre en otras comunidades Barrapunto permite el registro de sus usuarios, lo que les da la posibilidad de construir una identidad permanente y acceder a determinados privilegios: publicar una bitácora personal, calificar contribuciones de otros usuarios y personalizar distintos elementos ${ }^{15}$, y por supuesto es un requisito imprescindible para llegar a ser editor. 
El registro constituye para muchas comunidades un mecanismo fundamental para la regulación, un medio para evitar la participación indiscriminada e identificar a los usuarios que violen las normas de la comunidad ${ }^{16}$. No es el caso de Barrapunto, donde el registro no es obligatorio y se puede contribuir de forma completamente anónima. Barrapunto es una comunidad completamente abierta.

El mecanismo de registro establece en Barrapunto una distinción básica entre los usuarios con una identidad permanente tras haberse dado de alta (les llamaremos también miembros) y los usuarios no registrados, anónimos, cuyos comentarios se atribuyen genéricamente a la figura del pobrecito hablador. Existe además la categoría del editor.

El grupo de editores es una docena de personas en activo, aunque son más de 20 en total ${ }^{17}$, que se ocupan de la gestión diaria del sitio. Son los responsables de una de las funciones clave de Barrapunto, la selección de noticias que se publican en la portada. Son ellos quienes filtran entre todas aquellas que han enviado los usuarios las que aparecen en la portada, el espacio de mayor visibilidad $^{18}$.

Los usuarios anónimos, los pobrecitos habladores, pueden enviar noticias, escribir comentarios y acceder al mismo tipo de información que los demás. Hay usuarios que no sienten la necesidad de registrarse porque experimentan una mayor libertad cuando participan como un pobrecito hablador desde el completo anonimato ${ }^{19}$. Pero para participar plenamente en Barrapunto el registro y la creación de una identidad son elementos ineludibles, como veremos.

Mi identidad para el estudio de campo fue AlvaroDeCamposs. Necesité únicamente suministrar una cuenta de correo a la que me enviaron mi clave de acceso. A partir de ese instante podía comenzar a deambular por Barrapunto. Enseguida empecé a realizar comentarios y al poco envié mis primeras noticias. Pasadas unas semanas abrí mi bitácora.

La existencia de identidades permanentes es, según Peter Kollock, un elemento fundamental para el desarrollo de cooperación en comunidades del ciberespacio (Kollock, 1996; Kollock, 2002). Kollock traslada al ciberespacio el análisis que Ostrom y Axelrod hacen de la cooperación en comunidades off-line y concluye que es necesaria la existencia de una continua presencia en la comunidad así como la posibilidad de identificar al otro y conocer su trayectoria de participación para que la cooperación sea sostenible en el ciberespacio.

En Barrapunto uno construye su identidad contribuyendo, aportando información y opiniones, y no tanto a través del diálogo con los otros. Barrapunto orienta su dinámica -sobre todo en el espacio principal de la portada y las noticias- hacia una práctica muy concreta como es el intercambio de información, hacia la producción de información significativa ${ }^{20}$, a diferencia de otras comunidades más volcadas en la interacción social, como el chat ${ }^{21}$ o los MUD. Para musg1, un entrevistado, administrador de sistemas de 27 años que visita desde hace tiempo Barrapunto, la interacción social es algo secundario e incluso prescindible en el sitio: 
nunca he sentido esa necesidad de conocer al que tengo al otro lado, con distinguir sus ideas y sus cosas, y sus comentarios en el foro, no es como en el chat, que la gente parece que a todas horas se quiere reunir en un bar o en algo, para conocerse (E. P., musg1, 3)

En Barrapunto eres sobre todo lo que opinas, me dice Candyman: "no sabemos quien es la gente, ni queremos saberlo, esto permite cosas fascinantes... y es que tú eres tus opiniones" (E. P., Candyman, 4)

Registrarse significa estar expuesto a las valoraciones de los demás y construir un nexo de unión entre todas las contribuciones personales, que quedan recogidas en un historial de participación. Los historiales son públicos y en ellos se encuentra detallada la participación del usuario además de la descripción personal que uno haya dado (correo y página personal, ambos campos opcionales). A finales de mi investigación el historial de AlvaroDeCampos (figura 3) recoge que su karma ${ }^{22}$ es de 37 , que ha enviado 87 comentarios y figuran enlaces directos a los 24 más recientes con sus puntuaciones, que ha publicado 4 noticias y un enlace a su última bitácora. musg1 me explica así las razones para haberse registrado en Barrapunto:

te permite dar tus opiniones, como tú, como tu usuario, o sea, eres tú, el resto ya saben que es tu opinión, entonces al final con el tiempo, ya te conocen, más o menos quién eres, aunque todos los datos que pongas sean falsos, pero esa persona es un ente que alguien lo asume como una persona, alguien detrás de ese nombre es una persona, o sea no es pobrecito hablador que puede ser cualquiera, que un día malo ha empezado a poner todo chorradas y otro día hace comentarios interesantes, pero que sólo son de un día, con todo ese tiempo ya puedes discernir si te interesa seguir leyendo lo que dice porque igual es muy largo (E. P., musg1, 5)

Los usuarios de Barrapunto acumulan en sus identidades un capital simbólico que valoran y tratan de conservar. Detrás de una identidad hay alguien a quien se le pueden exigir cuentas, a quien se puede interpelar, alguien con una historia que asume las consecuencias de sus intervenciones, y esto, cuenta musg1 en la entrevista, no ocurre cuando se contribuye como un usuario anónimo:

yo creo que el gran problema es el anonimato, que a la gente cuando le das anonimato muchas veces hace cosas que no haría con su propio usuarios, entonces si tiene que cuidar esa imagen o lo que sea pues no cambia... (E. P., musg1, 7)

De manera que la comunidad privilegia a los usuarios que se han registrado concediéndoles más credibilidad que a quienes contribuyen desde el completo anonimato como pobrecitos habladores. A pesar de esto el anonimato es un valor en general compartido dentro de la comunidad, en la forma de pobrecito hablador se presenta como un elemento indispensable porque es la manera de asegurar que la comunidad está abierta a la participación de cualquiera, así opina Candyman:

Obligar al registro es un coñazo, si obligáramos al registro no tendríamos apenas comentarios, o no tendríamos comentarios del que viene sólo una vez, que esa persona es muy interesante, imagínate que mañana se pone una noticia... sobre IBM, y viene una persona que ni se registra y dice, yo trabajo en IBM, te escribe una cosa y no va a volver jamás, si a esa persona 
la obligaras a registrarse a lo mejor dice: "va para esto no vale la pena", y pederías ese comentario.

Cualquiera puede participar sin necesidad de acometer el proceso de registro. Pero mantener esta orientación implica enfrentarse a los desmanes provocados por quienes se amparan en el anonimato total $^{23}$. Por eso el pobrecito hablador es una figura con mala reputación, y por eso se concede más credibilidad a las palabras de quien tiene una identidad porque se sabe que quien está detrás de ella ha invertido su esfuerzo. musg1 señala la forma como la identidad sirve para reconocer al otro y valorar sus contribuciones por anticipado ${ }^{24}$ :

Si veo su nombre ya sé lo que me voy a esperar de ese mensaje porque ya le conozco de varios mensajes que he visto antes, entones yo creo que es eso lo que intentas firmando siempre con tu nombre, que la gente te reconozca aunque no tengan ni idea de quien eres ni nada y todos los datos que pongas sean falsos, que así también serías un usuario anónimo, pero estás contribuyendo desde una misma persona, y que ellos mismos pueden discernir si les interesa lo que tienes que decir tú o no, eso con el usuario anónimo o pobrecito hablador no se da (E. P., musg1, 1)

El mecanismo técnico del registro tiene como consecuencia directa la generación de una identidad permanente y la asignación de privilegios, pero la comunidad elabora su significado para la identidad, por el cual el usuario registrado no es principalmente uno que tiene más privilegios sino un usuario que goza de más credibilidad que el anónimo. El registro es un proceso sociotécnico que acredita a quien lo acomete. La comunidad ha construido su propio significado para la identidad de acuerdo a su objetivo de producción de información significativa.

Pero tener una identidad permanente y exponerse públicamente puede ser una carga. La identidad se convierte en ocasiones en un impedimento para participar de forma desinhibida. De ahí que algunos miembros registrados creen dobles identidades ${ }^{25}$ para eludir esa presión, en otras ocasiones los usuarios registrados deciden prescindir de su identidad y contribuir como anónimos, como un pobrecito hablador. La arquitectura técnica del sitio está dispuesta para facilitar este anonimato completo porque basta simplemente con marcar la casilla de "envío anónimo" para que nuestra identificación de usuario no aparezca en el comentario que hacemos (figura 4).

La identidad es el primer elemento organizador de la comunidad. Se genera a través del proceso de registro, un mecanismo sociotécnico cuyo significado se construye de acuerdo con el objetivo de la comunidad de producir información significativa. Los comentarios de un usuario tendrán diferente credibilidad si alguien los firma con una identidad permanente o como un pobrecito hablador anónimo. La identidad dota de credibilidad a las contribuciones de los usuarios, pero este mecanismo produce una tensión al enfrentarse con el ideal de participación abierta y libre expresión sin trabas de Barrapunto. Las contribuciones anónimas exponen a la comunidad al peligro de los alborotadores pero sirven al mismo tiempo como válvula de escape para los usuarios registrados. Es a través de los mecanismos sociotécnicos de registro y del pobrecito hablador, a través de la arquitectura técnica, como la comunidad trata de satisfacer ambos objetivos. 


\subsection{La visibilidad y el reconocimiento como factores motivadores}

Si la identidad demuestra ser un elemento básico para dotar de credibilidad a la información de los usuarios es igualmente un mecanismo fundamental para sostener la colaboración de los miembros de la comunidad. Es un elemento básico en la articulación de dos factores que funcionan como motivadores: la obtención de visibilidad y el reconocimiento público.

La visibilidad es sin duda el motivo que empuja a muchos usuarios a contribuir: saber que van a ser leídos, y mayor visibilidad significa aumentar las posibilidades de ser leídos por más gente ${ }^{26}$. La reputación ${ }^{27}$, el reconocimiento y el sentido de eficacia que obtienen los usuarios son importantes elementos que fomentan la participación y motivan en comunidades colaborativas, según Kollock (Kollock, 2002).

Tanto la visibilidad como el reconocimiento son funciones que la comunidad gestiona en Barrapunto a través de la moderación ${ }^{28}$, un mecanismo destinado a valorar la calidad de la información. Se realiza de forma distribuida por los usuarios que están registrados y consiste en la calificación de los comentarios de acuerdo a una serie de categorías (figura 5). Los comentarios que se califiquen positivamente ("interesante", "informativo", "ingenioso", etc.) suman un punto, los que se califiquen negativamente ("fuera de tema", "redundante", etc.) restan un punto. El valor total que puede alcanzar un comentario varía desde ' -1 ' hasta ' +5 '. Si un comentario tiene puntuación negativa hay bastantes posibilidades de que un número considerable de lectores no lleguen a leerlo. Cada punto que recibe un comentario se acumula en el karma del autor, una variable que mide el reconocimiento otorgado por la comunidad. Cuanto mayor es el karma de un usuario significa que más calificaciones positivas han recibido sus comentarios. El valor del karma puede ser negativo o alcanzar un máximo de 50 (figura 6).

Los puntos que un comentario recibe son importantes porque cuanto mayor sea la puntuación más relevancia tendrá el comentario, será más visible y estará expuesto a más lectores. Los usuarios que leen Barrapunto puede filtrar individualmente la información que desean leer fijando un umbral de lectura, cuyo valor varía entre '-1' y ‘+5'. Al establecer un umbral determinado sólo aparecen visibles los comentarios cuya puntuación sea igual o superior a ese valor (el resto de comentarios quedan contraídos bajo un hiperenlace).

No todos los usuarios pueden moderar comentarios en todo momento. Para hacerlo es necesario estar registrado (los anónimos no pueden). Para determinar qué usuarios pueden moderar un día determinado el mecanismo asigna aleatoriamente cinco puntos que tienen una vigencia de tres días para calificar las contribuciones de los demás. A medida que un usuario va puntuando (positiva o negativamente) comentarios se consumen los cinco puntos ${ }^{29}$. Además de cómo medida indicadora del reconocimiento acumulado el karma tiene la función de segmentar la visibilidad de los usuarios registrados.

Cuando me registré mi karma comenzó con un valor de 0 . No había puesto ningún comentario y por lo tanto no había recibido ninguna valoración (moderación). Al principio, mis contribuciones partían publicadas con un ' +1 ' por estar registrado, frente a los comentarios de cualquier pobrecito hablador que comienzan con un valor inicial de ' 0 ' puntos. Poco a poco y a medida que mis comentarios recibían puntos de moderación mi karma fue aumentando. Al cabo de unas semanas me pilló por 
sorpresa descubrir que mis contribuciones aparecerían publicadas con un '+2' de salida. Cuando el karma llega a 25 se produce el cambio. La confianza que la comunidad me había dado respaldaba mis contribuciones que desde ese momento gozaban de mayor relevancia. Mis opiniones eran más visibles que las de un pobrecito hablador o las de un usuario con un karma inferior a 25 puntos.

Candyman me explica las razones por las que los comentarios que hacen los usuarios registrados parten con más puntos y tienen mayor visibilidad de partida que los realizados por un usuario anónimo:

tus comentarios valen más [cuando eres un usuario registrado], porque se supone que has invertido, es una forma de meritocracia automatizada, entre todos los usuarios de Barrapunto con sus actos de moderación han acordado de algún modo que tus comentarios valen más sólo por el hecho de ser tú y tu historia pasada de comentar, entonces eso es para lo que vale el karma (E. P., Candyman, 1)

Resulta pues que la moderación, diseñada como un mecanismo destinado a calificar la información y facilitar su posterior filtrado a través del umbral de lectura estratifica a los usuarios según su grado de visibilidad en la comunidad (a través del karma). Aquellos que más participan de forma más relevante tienen un mayor karma y sus contribuciones son más visibles.

Hay por lo tanto un doble mecanismo de segmentación de la visibilidad de la información. Uno basado estrictamente en la calidad de la información, que la comunidad juzga y califica a través de la moderación en cada momento, puntuando las contribuciones. Cada comentario, independientemente de que lo haya realizado un usuario registrado o anónimo, se encuentra expuesto a este mecanismo y su visibilidad puede aumentar o disminuir, según los juicios particulares de los moderadores en cada momento. Un segundo mecanismo de segmentación de la visibilidad se apoya en la historia personal de los miembros de la comunidad, los registrados, y en el reconocimiento particular que cada uno de ellos ha recibido. A través de la moderación y el karma se estratifica a los usuarios por su grado de visibilidad.

El karma, al segmentar la visibilidad en la comunidad, constituye una de las funciones básicas para promover la participación y motivar a los usuarios ${ }^{30}$, y además, contribuye a consolidar las identidades permanentes ${ }^{31}$ porque el historial y el karma son para un usuario un importante capital social acumulado.

Los usuarios que no han alcanzado el máximo de karma tratan de lograrlo, aunque el karma se interpreta de forma muy dispar entre los usuarios más noveles y los más veteranos. Ver como asciende resulta gratificante y para algunos tener el karma máximo se convierte en una obsesión, como en el caso de DonekyMCP:

Con el tiempo, fui recogiendo puntos y puntos, hasta llegar a los 50.

Y ahora es casi como una obsesión (bueno, eso sería exagerar) simplemente que he llegado a considerar que tener 50 puntos de karma es lo normal, y que debe ser así.

Y no es que me moleste recibir algún "-1" como una colleja por soltar alguna tontería, es que me revienta que escriba algo que no es malintencionado y alguien lo modere como tal. Como aquí.

Para evitar una continua competencia por lograr que aumente el karma se ha fijado un valor máximo de $50^{32}$. En mi caso, y tras tres meses llegué a 37 puntos. Una vez que se alcanza el valor máximo el 
karma deviene un elemento estático y deja de motivar. Kepper dice: "prefiero tener 45 [puntos] o así para saber cuando me puntúan algo. Además me gusta tener esa necesidad de llegar a los 50 puntos, sino me aburro y mi instinto de superación también xD". Otros usuarios prefieren no darle importancia, especialmente los que llevan más tiempo registrados. Sí funciona, en cambio, como un elemento que motiva permanentemente la moderación de los comentarios.

VortixTM, por ejemplo, tiene muy presente y lo recuerda en un comentario que en tres años y medio participando sólo ha conseguido una puntuación máxima para sus comentarios de un "+4". Aloriel describe la atención que él, como otros usuarios, le presta a las moderaciones de sus comentarios:

yo creo que todo el mundo mira sus comentarios por ver si los han valorado bien o mal, siempre te interesa saber si a la gente le ha interesado tu respuesta, así que sí, particularmente me interesa si me quitan puntos o no (E. P., Aloriel, 5)

La moderación funciona como un sistema de reconocimiento distribuido y como un importante mecanismo motivador. Gracias a la moderación es posible mantener una arquitectura para la libre participación aun a costa de exponerse a los desmanes del anonimato. Los pobrecitos habladores son escuchados, pero saben que sus contribuciones parten con desventaja para ser tomadas en cuenta porque tienen menor visibilidad.

El sistema de moderación y la identidad son por lo tanto los mecanismos en torno a los que se articula la estratificación social de la comunidad. A partir de la identidad, a la que se accede a través del mecanismo de registro, se segmenta la credibilidad de los usuarios distribuidos en tres categorías: usuarios registrados, pobrecito hablador y editores. Un segundo nivel de estratificación refina esta clasificación al fijar diferencias en el grado de visibilidad entre cada grupo. Los comentarios de los pobrecitos habladores parten con visibilidad ' 0 ', los de usuarios registrados con karma menor que 25 parten con ' +1 ' y los usuarios registrados con karma mayor que 25 parte con '+2' (la visibilidad de los editores está sometida al mismo criterio que la los registrados).

\subsection{Pobrecito hablador: las tensiones del anonimato en un entorno abierto}

Pobrecito hablador es un mecanismo esencial en Barrapunto. Es una figura problemática y muy discutida. Su función fundamental es permitir que cualquiera participe sin necesidad de estar registrado y que cualquiera que esté registrado pueda opinar sin temor a ninguna represalia. Pobrecito hablador está ligado al ideal de comunidad abierta y libre expresión de Barrapunto porque asegura a los usuarios un mecanismo para el anonimato local absoluto.

Pobrecito hablador es en muchas ocasiones una fuente de tensión, por ejemplo en la aplicación de la moderación. Una de las cuestiones básicas es cómo valorar las contribuciones anónimas frente a las de miembros registrados. La moderación está diseñada para valorar opiniones independientemente de su autor, como reconoce un usuario: 
Valoro igual al mensaje escrito por un pobrecito hablador que por alguien con un UID de dos cifras... [un usuario antiguo] principalmente porque lo que modero es el comentario, no a la persona que lo escriba

Pero cada usuario genera su propio criterio. Hay quien lo establece distinguiendo entre usuarios registrados y anónimos, como señala en su bitácora trinuxfree:

1.- Puntuar siempre con puntos negativos a los usuarios anónimos, casi nunca, excepto en un comentario brillante o muy simpático, puntos positivos.

2.- Usar puntos positivos con los usuarios registrados.

La razones para adoptar este criterio son claras para trinuxfree: "los usuarios anónimos suelen ser los usuarios más simpáticos, con más comentarios fuera de tema y Troll. Los usuarios registrados suelen ser comentarios que no sobresalen, algunos simpáticos y brillantes, y los menos fuera de tema y Troll".

Al pobrecito hablador se le asocia una falta de credibilidad (comparado con los usuarios registrados) y una visibilidad rebajada a través del mecanismo de la moderación. Sobre el pobrecito hablador pesa la losa de la mala fama, como señala valis en un comentario en una bitácora:

Eres el paradigma del pobrecito hablador, entras en una historia que no te interesa, no aportas nada, te quejas amargamente de las "chorradas" que a los demás nos apetece contar(nos), con lo fácil que es no leer la entrada en la bitácora, sigue así hombre estás dignificando el nombre que portas.

Pobrecito hablador es una figura cuyas contribuciones carecen de coherencia. Es un "hijo de puta esquizofrénico", dice de él Candyman. Y esta falta de coherencia irrita a los miembros de Barrapunto. Sus intervenciones son brillantes, ingeniosas y mesuradas en muchas ocasiones, y ofensivas, inútiles y decididamente provocadoras en otras. No es extraño que en muchas ocasiones el pobrecito hablador adopte la forma de un troll, quizá uno de los fenómenos más desequilibradores a los que se enfrenta una comunidad abierta como Barrapunto.

Sin embargo, muchos usuarios reconocen la necesidad del pobrecito hablador como vía para asegurar el anonimato de sus contribuciones, como señala Tei: "Yo me siento identificado con los pobrecitos habladores, porque creo que el anonimato protege otros derechos"

Desde la acuñación de su nombre pobrecito hablador nace cargado de tensión por la pretensión de incentivar el registro como medio para evitar abusos y la aceptación de los anónimos como medio para la participación abierta $^{33}$. acs me explica de esta manera las razones para bautizar como pobrecito hablador a los usuarios anónimos:

la principal motivación para mantener ese tema [el pobrecito hablador] es provocar que los usuarios tener un aliciente para [que se] registren en el sitio, y sobre todo... porque la colaboración que tienes con Barrapunto no tienen nada que ver si estás registrado y eres alguien que en cierto modo utilizas tu nombre o tu nick para respaldar tus opiniones o simplemente eres alguien que llega en un momento, suelta una opinión y se esconde, que 
básicamente [es] lo que sería alguien que no se registra [...] teniendo así un nick, no sé si llamarlo, hiriente, o así un poco que te pueda sentar mal verlo, pues motivas al usuario que haga el esfuerzo de registrarse (E. P., acs, 1)

Pobrecito hablador es un mecanismo que se asocia al ideal de participación abierta de Barrapunto y que se mantiene ligado a la moderación. Sin ella, pobrecito hablador no sería posible. Cuando Tei dice que el pobrecito hablador asegura derechos fundamentales se refiere al anonimato: "yo es posible que nunca necesite "el pobrecito hablador", pero me alegra que exista por si algún día tengo que decir algo impopular". Un pobrecito hablador deja este comentario:

\begin{abstract}
Me gusta serlo [pobrecito hablador], porque me da la sensación de que lo único que me encorseta al hablar es mi propia conciencia. Es cierto que esto me podría conducir (como conduce a algunos) al trolleo y el porculeo sistemático, pero por contra también me hace cultivar mi conciencia cívica: no porque sea anónimo, debo tener menos responsabilidad. Digamos que Pobrecito Hablador es una identidad colectiva, que respetan aquellos que saben respetar la colectividad. En cierto modo, es lo mismo que cuidar del mobiliario urbano o no sacar el perro a cagar a la acera.
\end{abstract}

El pobrecito hablador podría suprimirse, hay otras comunidades basadas también en el mismo programa informático que Barrapunto, Slash, en las que no se admiten los comentarios anónimos ${ }^{34}$, pobrecito hablador ha sido suprimido, pero en Barrapunto se considera esencial.

Si la moderación es el mecanismo con el que la comunidad trata de alcanzar el objetivo de producir información significativa el pobrecito hablador es el mecanismo desarrollado para permitir la participación abierta y la libre expresión a través del anonimato sin necesidad de registro. Las tensiones que se desarrollan entre ambos objetivos son patentes. La comunidad mantiene el equilibrio de su dinámica permitiendo la presencia de los pobrecitos habladores a costa de concederles menor credibilidad y una visibilidad rebajada.

\title{
3. Filtrado colaborativo: de la producción de noticias a la regulación social
}

\subsection{La arquitectura técnica como fuente de regulación social}

Barrapunto es una comunidad sin reglas explícitas. Carece de netiqueta, no hay normas de estilo explicitas ni tampoco requisitos básicos para contribuir en el sitio. Los usuarios usan estilos de hiperenlaces muy diversos, por ejemplo, y citan las contribuciones de los demás de forma variada: usando cursivas, sangrando el texto, entrecomillándolo... algunos incluyen en sus mensajes enlaces a su página personal, su correo personal, etc, mientras otros usuarios no proporcionan ninguna forma de contacto. Ninguno de estos aspectos está reglado explícitamente ${ }^{35}$.

El sitio dispone únicamente de unas muy breves y generales $F A Q^{36}$, una explicación sobre el pobrecito hablador $^{37}$ y unas FAQ sobre la moderación ${ }^{38}$, una traducción de las escritas en inglés para 
Slashdot $^{39}$ (literalmente "Barrapunto"), el sitio de EE UU inspirador de Barrapunto. El software que usa Barrapunto, Slash, fue desarrollado por los responsables de Slashdot. Es un programa de software libre en permanente desarrollo, cualquiera puede usarlo gratuitamente y puede introducir modificaciones en él.

La labor de los editores es puramente editorial, reconocen que no tienen ninguna responsabilidad sobre la dinámica que se desarrolla en la $\operatorname{comunidad}^{40}$. La comunidad se autorregula mediante la moderación. No se borra ningún comentario pese a que existe un sencillo mecanismo que permite a los editores hacerlo con un solo clic (figura 5). El ideal de la participación abierta y libre arrincona el uso de este mecanismo.

No hay normas explícitas y es la arquitectura técnica el mecanismo que regula la comunidad, organiza la dinámica y pone orden en Barrapunto. Destinada al filtrado de información, la moderación acaba funcionando como un poderoso instrumento regulador de la conducta individual, como se verá, y de la organización política de la comunidad. Pero el significado de la moderación no está dado, sino que se construye dentro de la comunidad, como se ha visto más arriba.

\subsection{Del filtrado de la información a la regulación de las conductas}

La arquitectura técnica moldea a la comunidad ${ }^{41}$ y es moldeada a su vez por ella. La moderación es uno de los mecanismos centrales que permiten el filtrado de información. El otro mecanismo fundamental es la selección que los editores hacen de las noticias, pues son ellos quienes deciden cuáles pasan a la portada del sitio, el lugar con mayor visibilidad, y cuáles son rechazadas. Los editores constituyen el núcleo jerárquico de la comunidad y son un componente fundamental en la selección de la información.

Una parte fundamental de las noticias son sus comentarios, y es en el espacio de los comentarios donde el sistema de filtrado resulta fundamental. Como se ha dicho, la dinámica de Barrapunto está centrada en el filtrado de la información, un proceso complejo ${ }^{42}$ expuesto a innumerables problemas $^{43}$. La función formal de la moderación es "seleccionar lo que son joyas y lo que es simple ruido [...] el objetivo es que cada usuario lea Slashdot [y Barrapunto] al nivel que más le apetezca" ${ }^{44}$ y para ello recurre a la cooperación distribuida de los usuarios.

El filtrado es un proceso sofisticado que se realiza en dos partes. La comunidad califica primero de forma distribuida la información mediante la moderación y cada usuario establece después un umbral de lectura individual (que va desde ' -1 ' a ' +5 ') mediante el cual cada uno sólo verá los comentarios cuya puntuación sea igual o mayor al umbral. Hay un componente colectivo y otro individual en el proceso que son de gran importancia.

Pero si la moderación tiene como función original valorar las informaciones independientemente de quién las haya realizado, la moderación acaba por tener una importancia fundamental en aspectos para los que no fue diseñada, como por ejemplo la regulación de las conductas individuales. Ya se ha visto en la sección 2.3 cómo a través de la moderación la comunidad refina la estratificación social en Barrapunto y cómo funciona como un sistema de reputación, un tipo de sistemas de gran importancia en la regulación de los comportamientos en una comunidad ${ }^{45}$. 
Los usuarios están expuestos en todo momento en Barrapunto a los juicios de los demás, al enviar una noticia, al publicar en tu bitácora, cuando haces un comentario. Cualquiera puede publicar una réplica a lo que tú has escrito. La moderación es un mecanismo de exposición mucho más potente. Es rápido, anónimo y expeditivo. "No sabía si moderarte o contestarte a este comentario, pero te voy a contestar", dice alguien antes de comenzar su diatriba contra el comentario de otro usuario. Esta circunstancia lleva a los usuarios a auto-regularse, como una forma de proteger su reputación frente a malas moderaciones, así me lo cuenta agente_naranja:

decir algo y que luego te puedan quitar puntos parece que.. parece que... no sé si será eso pero yo creo que sí que a la gente que le da un poco corte que le quiten un punto y que digan, oye a ver si van a pensar de mí que soy aquí un metepatas o que voy provocando (E. P., agente_naranja, 2)

Ya se ha señalado cómo en algunas ocasiones los usuarios recurren al pobrecito hablador anónimo para proteger su reputación y no exponerla frente a la calificación de los otros a través de la moderación. La arquitectura técnica está dispuesta para que esto se haga fácilmente, con un solo clic los comentarios se envían de forma anónima (figura 6).

La moderación funciona por lo tanto como un sofisticado mecanismo regulador de las conductas individuales. Se ha visto cómo el karma y la moderaciones puntuales de los comentarios son mecanismos motivadores para los usuarios. Es la exposición al reconocimiento colectivo que se gestiona a través de la moderación lo que lleva a los usuarios a ser comedidos en sus conductas, no por el cumplimiento de unas normas que no están codificadas, sino por sentirse expuestos a las valoraciones expeditivas del resto de usuarios. El proceso de jerarquización de la información se transforma de esta manera en el regulador social de la comunidad.

\subsection{La política contextual del filtrado de la información}

La política de Barrapunto se hace a través de su arquitectura técnica. Barrapunto es una comunidad con una jerarquía mínima ${ }^{46}$. La capacidad de intervención de los editores es limitada, más exactamente autolimitada. Tratan de intervenir lo mínimo en la regulación de los espacios, por ejemplo deciden prescindir del privilegio de borrar los comentarios.

Todos los usuarios, registrados o no y los editores, tienen acceso a la misma información. Hay una distribución de roles basada en las funciones. Los editores no asumen prácticamente ninguna función reguladora en la comunidad ${ }^{47}$. No arbitran en los debates que se desarrollan, "no hacemos trabajo de censura ni de pastoreo, para eso existe la moderación", explica Candyman en la entrevista. Se deja que la dinámica se regule a través de la moderación.

Es muy interesante la explicación detallada que da CmdrTaco (Anexo 1), uno de los fundadores de Slashdot y desarrollador del sistema de la moderación, de cómo surge esta en Slashdot y cómo está ineludiblemente ligada al aumento del número de usuarios en la comunidad. CmdrTaco explica en las FAQ recogidas en Barrapunto ${ }^{48}$ cómo surge la moderación: 
Entonces comencé a trabajar en la siguiente etapa: moderación en masa. Aprendí bastantes cosas al tener tantos moderadores. Tenía que limitar el poder de cada persona para prevenir que uno se dedicara a desclasificar a los demás. $Y$ entonces vino el siguiente paso: Hoy cualquier lector habitual de Slashdot puede ser elegido para moderar.

A través de la moderación se delega lo que antes era una actividad realizada por unos pocos individuos en un gran colectivo, y a través de ella se intenta evitar privilegiar a un grupo ${ }^{49}$. La política se delega en la comunidad a través de un sistema que pretende ser no-conflictivo, aunque finalmente no resulte así, como se verá seguidamente.

Hay una firme convicción entre los usuarios de Barrapunto de la importancia que tiene la moderación para el funcionamiento de la comunidad aunque existe una notable disparidad y tensiones derivadas de dos aspectos: (i) el criterio con el que debe realizarse y (ii) el grado de efectividad que la moderación tiene en cada momento. Candyman responde a la cuestión sobre la función que se asigna a la moderación:

¿Qué función le damos [a la moderación]?, la que le da el lector... yo te respondería... tú, como lector de Barrapunto, ¿qué función le das a la moderación?... la función del que lee a menos uno es leerlo todo, la del que lee a cuatro es ahorrarse tiempo (E. P., Candyman, 10)

Hay quienes consideran que debería moderarse de forma "objetiva", "imparcial", como señala la guía de moderación ${ }^{50}$, que deberían valorarse positivamente aquellos comentarios que estén "bien razonados y argumentados" aunque uno no comparta esas opiniones. Hay quien propone como norma moderar a la baja a los pobrecitos habladores que son anónimos y usar las moderaciones positivas para los usuarios registrados. En estas controversias se negocia públicamente el significado de la moderación, más allá de lo que se establece en sus FAQ.

La percepción de algunos usuarios es que la moderación no se ejerce correctamente y que mediante la moderación se excluye a una parte de la comunidad, bac critica este hecho en un hilo de discusión en una bitácora:

El problema está en que mucha gente no entiende bien el significado de moderar. Para mucha gente moderar es poner +1 a la gente que piensa igual que uno (esta en lo cierto!) y -1 a uno que piensa diferente (está equivocado!)

Y esto lleva a la exclusión del debate de aquellos que no participan del pensamiento dominante en la comunidad, según consideran algunos. La moderación permite "crear una meritocracia dictatorial, en el que los que tengamos 50 puntos podemos gastar karma [el usuario se refiere en realidad a los puntos de moderación ya que uno no puede gastar su karma] a mansalva para tumbar al resto que no nos guste". musg1 me cuenta cómo aflora en su opinión el integrismo a través de la moderación:

creo que la moderación tiene mucho que ver en cómo se desenvuelve la comunidad, o el foro, como lo quieras llamar, porque [...] si alguien hace un comentario razonado sobre el software propietario y se le puntúa negativo porque está hablando de software propietario esa moderación está mal hecha, entonces aunque puedes metamoderar y tal, pero esa persona que ve que todo el rato le están puntuando negativamente aunque sus ideas están bien 
expuestas y permiten una buena discusión pues esa persona dirá estos son integristas y dejará de ir al sitio (E. P., musg1, 14)

La moderación soslaya aspectos controvertidos al distribuir los privilegios de la calificación de la información, pero a la hora de establecer un criterio y unos objetivos claros para su aplicación afloran las tensiones.

El sistema de moderación proviene de Slashdot, un sitio con un número de noticias, comentarios y lectores mucho mayor. Hay quien considera que Barrapunto carece de la masa crítica que se necesita para que funcione la moderació $n^{51}$. En diciembre de 2003 toptnc escribía:

ahora mismo Barrapunto está en ese número crítico de usuarios en el que el nivel de ruido puede volverse insoportable y mas vale que utilicemos de forma debida la moderación para atenuar ese ruido o se pueden avecinar tiempos difífiles.

Hay quien atribuye el problema a que no hay la misma cultura de moderación que en Slashdot, o que se debe a una cuestión idiosincrásica: "somos españoles, los españoles tenemos muy mala ostia y muy mala sangre. Esto explica porque aquí se usan mas los negativos que los positivos", dice Tei en una discusión sobre la moderación, o que los temas de Barrapunto han cambiado hacia asuntos más sociales y resultan más propicios para los enfrentamientos, o que sencillamente han llegado más trolls a Barrapunto. Candyman da su opinión particular en la entrevista en la que recoge un par de aspectos:

la moderación de Slashdot, que técnicamente es la misma que la nuestra, con sus defectos, funciona mejor que la moderación de Barrapunto. La primera [razón para explicarlo] es que necesitas masa, entonces hay muchísimos más lectores en Slashdot, muchas más noticias, y la moderación es cada vez más útil y funciona mejor. Y la segunda [razón] es que en Slashdot la cultura de estos temas es más alta con frecuencia. (E. P., Candyman, 5)

La deficiencias en la moderación no se atribuyen a la arquitectura técnica, ¿o sí?. El mismo sistema funciona en Slashdot, como reconoce Candyman, ¿por qué no funciona en Barrapunto?: la moderación funciona mal por una cuestión cultural, debido a la magnitud de la comunidad...

Todo ello apunta a que la moderación constituye un mecanismo que necesita ser contextualizado en la comunidad que la utiliza. Necesita que la masa de la comunidad esté ajustada con el algoritmo y que el algoritmo se ajuste a la comunidad, que la comunidad desarrolle su propia cultura de moderación. La moderación puede contemplarse como un conjunto de líneas de código informático o como un mecanismo sociotécnico complejo en el que se mezclan componentes heterogéneos: criterios de aplicación, líneas de código informático, idiosincrasia de los usuarios, objetivos de aplicación, etc.

A través de la moderación la comunidad organiza su política informacional. La actividad principal de la comunidad, la producción de información significativa, está mediada por la moderación. Es el filtrado de la información a través de la moderación el que realza determinadas contribuciones y silencia otras. Si la moderación, como mecanismo de aplicación puntual, sirve de regulador de las conductas individuales, en su aplicación global la moderación da forma a la comunidad, dotando de visibilidad a 
unos temas, unas contribuciones, unos usuarios, y silenciando otros. La política de la comunidad se hace, por lo tanto, a través de los mecanismos de filtrado de la información.

\subsection{Trolls: el desafío del desorden en una comunidad abierta}

Hay diferentes funciones en Barrapunto que han sido confiadas a dispositivos técnicos en los que la acción humana es muy limitada. La distribución automática de la moderación es un ejemplo. Otro más son los sistemas para protegerse de ataques en masa, el envío de decenas de comentarios repetidos ${ }^{52}$.

Pero hay determinados ataques y comportamientos que no puede ser evitados usando únicamente procedimientos técnicos. El troll es uno de estos y constituye una de las principales amenazas en una comunidad abierta.

Los trolls aparecen en las conversaciones con ánimo de provocar sutilmente el conflicto, deslizando mensajes que suscitan la polémica y provocan una escalada del conflicto. Si el mensaje de un troll surte efecto puede resultar muy costoso en términos de alteración del orden regular en la comunidad $^{53}$. DanielSan describe así en un comentario lo que es un trol ${ }^{54}$ :

Un "troll" es una persona cuyos mensajes (molestos o no) buscan manipular los puntos sensibles de los participantes del hilo [de discusión] haciendo que se distraigan del tema central o estirando demasiado ciertas cuestiones de forma que consiga que se hable de un tema mucho más polémico.

Un típico "troll", por ejemplo, puede ser capaz de convertir un diálogo pacífico en una discusión acalorada (un "flame") que haga que las personas adopten posturas defensivas u ofensivas que compliquen el diálogo. Un "troll" muy refinado puede ser difícil de distinguir, e incluso a menudo un exceso de "desconfianza" puede hacer que alguien acuse de troll a alguien que no tenía intención de molestar. Por ejemplo, tú podrías ser un troll que sabe perfectamente de lo que hablo pero sólo quiere reírse de los demás. En ocasiones se hacen pasar por gente inexperta que hace preguntas "comprometedoras".

Como dice al final de su mensaje "tú podrías ser un troll que sabe perfectamente de lo que hablo" refiriéndose al usuario a quien responde. No es extraño que en ocasiones los usuarios tomen precauciones en mensajes que pueden resultar polémicos y adviertan por anticipado que su contribución es "sin ánimo de trollear".

Responder a un troll es una tentación porque ha sido diseñado para eso, para provocar una respuesta ${ }^{55}$. "No contestes jamás a un troll", es la recomendación de un pobrecito hablador en un comentario. Para detectarlos, para distinguir quién desliza una provocación y quién simplemente es un novicio hay que conocer los entresijos de la comunidad y su cultura. Para combatirlos Barrapunto usa la moderación.

Está muy extendida la idea de que muchos pobrecitos habladores contribuyen como trolls, excluirlos es relativamente sencillo, basta un punto de moderación negativa. Diferente son los trolls recurrentes, 
con una identidad definida en Barrapunto, algunos de los cuales llegan a convertirse en figuras conocidas y se ganan el favor y la complicidad de algunos miembros.

"¿Y tú?" es la marca identificativa de un troll famoso que algunos consideran gracioso. Arnesto es otro ejemplo de troll afamado cuya respuesta básica a otros comentarios es "¿cómeme el porro?". Pero es a Reginaldo Martínez a quien se considera un "troll de categoría" que goza de incondicionales. Sus opiniones son de apariencia correcta, argumentadas y están bien redactadas. Los comentarios de Reginaldo son los propios de quien calificaríamos como un integrista religioso católico. A mediados de 2003 desapareció de Barrapunto para hacer una par de intervenciones un año después, a principios de agosto de 2004. Reginaldo tiene un abultado número de comentarios calificados con "0" y "-1" en su historial.

Su segundo comentario a principios de agosto es calificado como "fuera de tema", pero el comentario de Reginaldo ha recibido 16 respuestas. Su mensaje está escrito en un tono correcto, incluso a mí me cuesta comprender por qué ha sido calificado con un "-1" como "fuera de tema". Fuera del contexto de Barrapunto no podría calificarlo como una provocación, sólo quien pertenece a la comunidad de Barrapunto apreciará donde está la sutil provocación de Reginaldo.

Reginaldo es un "troll profesional" que forma parte de la comunidad. Ya hemos visto más arriba la crítica de algunos usuarios hacia lo que consideran el integrismo de Barrapunto, y Reginaldo pone al descubierto las debilidades ideológicas de la comunidad, según un pobrecito hablador:

me congratulo de que vuelve usted a este foro a encandilarnos con sus perlas de sabiduría. Es usted capaz de, con tan solo dos oraciones (que no frases), poner usted el dedo en la llaga de la patulea abyecta que puebla este foro. Usted como nadie escandaliza a aquellos que eligieron autonombrarse inescandalizables del mundo en nombre de la progresía bienpensante y el comunismo descafeinado de salón. Deja usted en evidencia la fragilidad de las falacias exhibidas por los maleantes, piratas informáticos, ciberterroristas y pornógrafos que contaminan la pureza de nuestra Internet. Usted Reginaldo, Don Reginaldo, el inimitable, insustituible...

\section{La organización social a través de la producción informacional}

Las comunidades en el ciberespacio no son simples colectivos de humanos alojados en un asentamiento digital, sino artefactos culturales mezcla de elementos heterogéneos, humanos y no humanos, sociales y técnicos, etc.

Las comunidades de producción colaborativa son un caso muy especial de comunidad en el ciberespacio. Algunas de estas comunidades han demostrado ser verdaderamente efectivas en la 
producción de objetos informacionales significativos para los miembros de la comunidad e incluso para algunos que no pertenece a ella.

El sostenimiento y el desarrollo de estas comunidades colaborativas está expuesto a innumerables desafíos. Uno de ellos proviene de la participación abierta. Las comunidades abiertas que persiguen la producción de información significativa y aun así permiten el anonimato se enfrentan a todo un desafío. El anonimato absoluto impide que las represalias contra los individuos que violan las normas de conducta de una comunidad tengan vigencia a largo plazo. Conciliar el ideal abierto con el objetivo de producir la información más relevante posible no es una tarea sencilla.

El presente estudio demuestra la tensión que emerge en un entrono abierto entre el objetivo de producir información significativa mientras se permite la libre participación de cualquiera. Pero Barrapunto es sólo uno más de los muchos ejemplos que pueden encontrarse de comunidades abiertas de este tipo. En este caso la tensión emergente se resuelve mediante un doble mecanismo sociotécnico que por un lado permite el completo anonimato asegurando la libre participación y por otro lado, otro mecanismo que filtra la información más significativa para la comunidad.

Pero no es el único problema al que se enfrenta una comunidad dedicada a la producción de información y noticias. Otra de sus cuestiones fundamentales es asegurar la participación de los usuarios, mantener su motivación para contribuir. Son los procesos de filtrado de la información los que tienen una función fundamental en la resolución de ambas cuestiones. A través del filtrado de la información se lograr mantener la motivación de los usuarios, y en el caso de la comunidad estudiada, donde apenas existen normas sociales explícitas, los mecanismos de filtrado tienen una importante función en la dinámica social de la comunidad.

Barrapunto revela la íntima conexión que existe en las comunidades colaborativas de carácter meritocrático entre la producción y selección de información y la organización social. Los procesos de filtrado de la información producen primero una estratificación social basada en la credibilidad de los individuos y segmentan después la visibilidad de las opiniones en función de que estas provengan de usuarios registrados o anónimos. Son los mecanismos de jerarquización de la información los que estratifican y organizan socialmente a la comunidad.

Es por lo tanto a través de los mecanismos de filtrado como se organiza socialmente la comunidad. Y es a partir de propiedades asociadas a la información (credibilidad y visibilidad) como se construye la estratificación social de la comunidad. La organización social de la comunidad deriva por lo tanto de los sistemas sociotécnicos de producción informacional.

El estudio abre nuevas líneas de investigación dentro del marco de los nuevos medios y del fenómeno de los weblogs, una nueva modalidad de comunicación. El weblog constituye un artefacto sociotécnico que es el centro de tres realidades como son la identidad del autor, la comunidad de lectores que se reúne en torno a él y la acción colectiva de las redes de afinidad en las que se agrupan los weblogs. Tras la presente investigación se abre la posibilidad de plantear sobre la weblogosfera una etnografía simétrica y multisituada que acometa el estudio de este fenómeno en sus tres facetas: el weblogs como instrumento para la construcción de la identidad individual de sus 
autores, el weblog como micro-comunidad de productores de información y consumidores de ella y el weblogs y la weblogosfera, como conjunto de redes de weblogs, como instrumento para la acción colectiva.

\section{Referencias}

Aibar, Eduard; Miralles, Laia y Vayreda Agnès. Sociedad mediada por ordenador: hacia un análisis constructivista de las comunidades virtuales. En CABALLERO, D.; MÉNDEZ, M.T.; PASTOR, J. (eds.). La mirada psicosociológica. Grupos, procesos, lenguajes y culturas. Madrid: Biblioteca Nueva, 2000 (65-69). Extraído el 3 de octubre de 2004, de http://www.uoc.edu/in3/gircom/pdf/Actes_Oviedo.pdf

Ardèvol, Elisenda; Callén, Blanca; Beltrán, Marta y Pérez, Carmen (2003). Etnografía virtualizada: la observación participante y la entrevista semiestructurada en línea. Athenea Digital, 3 [En línea] <http://antalya.uab.es/athenea/num3/ardevol.pdf> [Consulta: 3 octubre 2004].

Axelrod, Robert (1984). The Evolution of Cooperation. New York: Basic Books.

Baym, Nancy K. The Emergence of On-line Community (1998). En Jones, Steve G. (Ed.), Cybersociety 2.0. Revisting Computer Mediated commmuniactions and Community. California: SAGE Publications.

Benkler, Yochai (2002). Coase's Penguin, or Linux and the Nature of the Firm. Yale Law of Journal. 112.

Bijker, Wiebe. E.; Hughes, Thomas P. y Pinch, Trevor (Eds.) (1989). The Social Construction of Technological Systems. $1^{\text {a }}$ ed. Camrbidge: MIT Press.

Bijker, Wiebe. E (1995). Of Bicycles, Bakelites and Bulbs. Towards a Theory of Sociotechnical Change. $1^{\mathrm{a}} \mathrm{ed}$. Cambridge (Mat.): MIT press.

Bowman, Shayne y Willis, Chris (2003). We Media. How audiences are shaping the future of news and information. NDN Research Report. Extraído el 5 de septiembre de 2004, de http://www.ndn.org

Casacuberta, David (2003). Creación Colectiva. En Internet el público es el creador. $1^{\mathrm{a}}$ ed. Barcelona: Gedisa.

Chan, Anita J. Collaborative News Networks: Distributed Editing, Collective Action, and the Construction of Online News on Slashdot.org. Tesis del Massachusets Institue of Technology. Extraído el 5 de septiembre de 2004, de http://web.mit.edu/anita1/www/thesis/Intro.html

Contreras, Pau (2004). Me llamo Kohfam. Identidad hacker; una aproximación antropológica. $1^{\mathrm{a}}$ ed. Barcelona: Gedisa.

Doménech, Miquel y Tirado, Francisco. J. (Eds.) (1998). Sociología simétrica. Ensayos sobre ciencia, tecnología y sociedad. $1^{\mathrm{a}}$ ed. Barcelona: Gedisa. 
Ghosh, Rishab A (1998). Cooking pot markets: an economic model for the trade in free goods and services on the Internet. First Monday, 3 (3). Extraído el 30 de septiembre de 2004, de http://www.firstmonday.dk/issues/issue3_3/ghosh

Hauben, Ronda (2001). Usenet and the Usenet Archives: The Challenge of Building a Collaborative Technical Community. Extraído el 4 de septiembre de 2004, de http://www.itas.fzk.de/esociety/preprints/mediaculture/Hauben.pdf

Hine, Christine (2000). Virtual Ethnography. 1ª ed. Londres: SAGE.

Howard, Philip (2002). Network ethnography and the hypermedia organization: new organizations, new media, new methods. New media \& society. 4 (4), 551-575.

Iranzo, Juan M. y Blanco, José R. (1999). Sociología del conocimiento científico. $1^{\mathrm{a}}$ ed. Madrid: CIS.

Jones, Quentin (1997). Virtual-Communities, Virtual Settlements \& Cyber-Archaeology: A Theoretical Outline. Journal of Computer Mediated Communication. 3 (3). Extraído el 23 de diciembre de 2003, de http://jcmc.huji.ac.il/vol3/issue3/jones.html

Jones, Steven. G. (Ed.) (1997). Information, Internet, and Community: Notes Toward an Understanding of Community in the Information Age. En Jones, Steven G. (Ed.). Cybersociety 2.0. Revisiting Computer-Mediated Communication and Community. Thousand Oaks: SAGE Publications, 1-34.

Kollock, Peter (1996). Design Principles for Online Communities". First International Harvard Conference on the Internet and Society. Extraído el 4 de septiembre de 2004, de http://www.sscnet.ucla.edu/soc/faculty/kollock/papers/design.htm\#Footnote\%201

Kollock, Peter (1999). The Production of Trust in Online Markets. En Lawler, Edward J. [et alt.] (Eds.). Advances in Group Processes. 16. Greenwich, CT: JAI Press. Extraído el 5 de septiembre de 2004, de http://www.sscnet.ucla.edu/soc/faculty/kollock/papers/online_trust.htm

Kollock, Peter (2003). Regalos y bienes públicos en el ciberespacio. En Smith, Marc y Kollock, Peter. (Eds.). Comunidades en el Ciberespacio. $1^{\mathrm{a}}$ ed. Barcelona: Editorial UOC, 259-282.

Kollock, Peter y Smith, Marc. Managing the Virtual Commons: Cooperation and Conflict in Computer Communities, 109-128. En Herring, Susan (Ed.) (1996). Computer-Mediated Communication: Linguistic, Social, and Cross-Cultural Perspectives Amsterdam: John Benjamins. Extraído el 5 de septiembre de 2004, de http://research.microsoft.com/ masmith/Vcommons.htm>

Lampe, Cliff., Resnick, Paul (2004). Slash(dot) and Burn: Distributed Moderation in a Large Online Conversation Space. Proceedings of ACM CHI 2004 Conference on Human Factors in Computing Systems. Vienna, 543-550. Extraído el 12 de octubre de 2004, de http://www.si.umich.edu/ presnick/papers/chi04/

Latoru, Bruno y Callon, Michel (1981). Unscrewing the Big Leviathan: How Actors Macrostructure Reality and How Sociologists Help Them Do It. En Knorr-Cetina, K.aren; Cicourel, Aaron V. (Eds.). Advances in Social Theory and Methodology: Toward an Integration of Micro- and Macro-Sociologies. Boston: Routledge. 
Paccagnella, Luciano (1997). Getting the Seats of Your Pants Dirty: Strategies for Ethnographic Research on Virtual Communities. Journal of Computer Mediated Communication. 3 (1). Extraído el 4 de septiembre de 2004, de http://www.ascusc.org/jcmc/vol3/issue1/paccagnella.html

Rafaeli, Sheizaf y LaROSE, Robert (1993). Electronic bulletin boards and "public goods" explanations of collaborative mass media. Communication Research, 20 (2) 277-297.

Raymond, Eric S. The Cathedral and the Bazaar. Versión 1.51. Extraído el 24 de agosto de 2000, de http://www.catb.org/ esr/writings/cathedral-bazaar/cathedral-bazaar/

Reid, Elizabeth M. (2003). Jerarquía y Poder. El control social en el ciberespacio. En Smith, Marc y Kollock Peter (Eds.) Comunidades en el Ciberespacio. $1^{\text {a }}$ ed. Barcelona: Editorial UOC, 149183.

Reid Elizabeth M (1991). Electropolis: Communication and Community On Internet Relay Chat. Tesis de la Universidad de Melbourne. Extraído el 4 de septiembre de 2004, de http://eserver.org/cyber/reid.txt

Resnick, Paul (2000). [et alt.]. Reputation Systems. Comunicaciones de la ACM. 43 (12). Extraído el 5 de septiembre de 2004, de http://smg.media.mit.edu/library/resnickReputationACM.pdf

Rheingold, Howard (1991). La Comunidad Virtual. Una sociedad sin fronteras. $1^{\mathrm{a}}$ ed. Barcelona: Gedisa.

Smith, Marc y Kollock Peter (2003). Las comunidades en el ciberespacio. En Smith Marc y Kollock Peter. (Eds.) Comunidades en el Ciberespacio. $1^{\text {a }}$ ed. Barcelona: Editorial UOC, 19-47.

Stalder, Felix y Hirsh, Jesé (2002). Open Source Intelligence. First Monday, 7 (6). Extraído el 4 de septiembre de 2004, de http://firstmonday.org/issues/issue7_6/stalder/index.html

Turkle, Sherry (1997). La Vida en la pantalla. La construcción de la identidad en la era de Internet. $1^{\mathrm{a}}$ ed. Barcelona: Paidós.

Wellman, Barry (1999). The Network Community: An Introduction. En WELLMAN, B. (ed.). Networks in the Global Village: Life in Contemporary Communities (pp. 1-47).. Boulder: Westview Press.

Wellman, Barry y Gulia, Milena (1999). Net-Surfers Don't Ride Alone: Virtual Communities as Communities, 331-366. En Wellman, Barry. (Ed.). Networks in the Global Village: Life in Contemporary Communities. Boulder: Westview Press.

\footnotetext{
${ }^{1}$ Véase por ejemplo el caso de Usenet descrito por Hauben en (Hauben, manuscrito inédito)

${ }^{2}$ Véanse los problemas a los que se enfrenta genéricamente la cooperación citados por Kollock (Kollock, 1996) a partir de los trabajos de Axelrod (Axelrod, 1984) y Ostrom (Ostrom, 1990).

${ }^{3}$ En lo que sigue usaré el término Linux para referirme al sistema operativo GNU/Linux. Linux es nombre del core (núcleo) del sistema, pero el sistema operativo completo contiene numerosos
} 
componentes de software desarrollado por la GNU Foundation, por tanto, la comunidad suele establecer que de forma estricta debe denominarse al sistema operativo GNU/Linux, usaré sin embargo el término Linux por razones de simplicidad y porque es el término que comúnmente se utiliza.

${ }^{4}$ Para una descripción de la historia y desarrollo de Linux puede verse (Wayner, 2001)

${ }^{5}$ Los estudios académicos sobre weblogs han sido limitados hasta ahora. Para un análisis sobre el origen e historia de los weblogs puede consultarse (Blood, 2000).

${ }^{6}$ Véase los ejemplos que Benkler pone de lo que el denomina producción compartida entre iguales (common-based peer production) en (Benkler, 2002).

${ }^{7}$ Véase en la sección 1.4 la parte dedicada a la construcción de la identidad del investigador donde se establece el marco teórico para la identidad.

${ }^{8}$ Véase (Iranzo, J. M. y Blanco, J. R., 1999: 381-384)

${ }^{9}$ Bijker usa el término sociotechnical ensemble, mientras otros autores usan términos similares como sociotechnical system, sociotechnical network, dispositivo socioténico, etc.

${ }^{10}$ Sobre la dificultad para la construcción de la identidad del investigador en el ciberespacio puede consultarse el estudio de Contreras (Contreras, 2003:63-78) o el trabajo de Ardèvol (Ardèvol et alt., 2003:6-9).

${ }^{11}$ Pueden consultarse las diferentes imágenes tomadas de Barrapunto al final del documento en el anexo 3, pág. 32 y siguientes.

$12\left({ }^{\star}\right)$ Las entrevistas están citadas según el formato: (E. P. nombre del autor, número del párrafo de la cita).

${ }^{13}$ El papel central de los usuarios en la producción de información y noticias en un sitio como Barrapunto es puesto de manifiesto por Anita Chan en su estudio sobre Slashdot, véase (Chan, 2002).

${ }^{14}$ Véase la guía de moderación en <http://barrapunto.com/moderation.shtml>.

${ }^{15}$ Como por ejemplo eliminar las noticias publicadas por determinados editores, o aquellas relativas a algunos temas, fijar algunos de los elementos que aparecen en la portada del sitio, etc.

${ }^{16}$ Véase en (Reid, 2003) cómo en los MUD hay diversos mecanismos que pretenden incentivar el registro de los usuarios.

${ }^{17}$ Véase la lista de los editores en <http://barrapunto.com/authors.pl>.

${ }^{18}$ El grupo se coordina básicamente a través de una lista de correo a la que sólo ellos tienen acceso y donde se discuten asuntos de la gestión diaria del sitio (errores en la redacción, noticias que deben publicarse, etc.). La elección de los editores se realiza a propuesta de alguno de los miembros del grupo. Uno de ellos propone, en general, que algún usuario registrado de Barrapunto que destaca por sus contribuciones o por su bitácora, y si nadie pone objeciones se cursa la invitación para que se incorpore al grupo de editores.

${ }^{19}$ Sobre la desinhibición que proporciona el anonimato o pseudo-anonimato en las comunidades virtuales puede verse para el caso de los MUD el estudio de (Reid, 2003). 
${ }^{20}$ Gray Burnett clasifica las comunidades según estén centradas específicamente en el intercambio de información o funcionen como un foro para intercambiar información y desarrollar actividades "socio-emocionales", (Burnett, 2000).

${ }^{21}$ Véase (Mayans, 2002:106) donde se describe el chat como un entorno enfocado hacia la interacción social.

${ }^{22}$ En la siguiente sección se explica en qué consiste el karma.

${ }^{23}$ Sobre los problemas que puede causar tanto el anonimato como la libre participación no moderada en las comunidades puede verse el caso descrito por Reid en el JennyMUSH (Reid, 2003: 160), o la destrucción de la comunidad CommuniTree tras la llegada masiva de adolescentes (Flichy, 2003: 98), caso relatado también por (Stone, 1993).

${ }^{24}$ Los usuarios de los grupos de noticias de Usenet usan como principal guía para seleccionar los mensajes el nombre del autor y las dimensiones del mensaje, como constatan en su estudio (Fiore et alt., 2002:3).

${ }^{25}$ No es la única comunidad en la que esto ocurre. Véase por ejemplo en (Contreras, 2003) cómo los hackers dedicados a piratear tarjetas de televisión digital usan distintas identidades con funciones diferentes.

${ }^{2626}$ El karma no es el único mecanismo para el aumento de visibilidad. Las bitácoras son instrumentos tremendamente efectivos en la construcción de la identidad en Barrapunto y son espacios que dan una gran visibilidad a sus usuarios. Otro elemento destinado al aumento de visibilidad de aquellos usuarios más activos son las secciones como 'Top Usuarios por número de entradas en la Bitácora' <http://barrapunto.com/journal.pl?op=top> en la que se recogen las 15 bitácoras con mayor número de entradas, al igual que la sección 'Lo más' $<$ http://barrapunto.com/hof.pl>, donde queda constancia de los usuarios más activos.

${ }^{27}$ Véase como la reputación, la creación de un nombre, y la fama dentro de un MUD son importantes elementos que contribuyen a mantener a los usuarios implicados en los MUD (Reid, 2003)

${ }^{28}$ Véase el anexo 2 donde se da una descripción del origen de la moderación.

${ }^{29}$ Para que un usuario pueda moderar debe llevar varias semanas registrado, tener un karma positivo y no ser un visitante compulsivo ya que se intentan evitar perfiles extremos entre los moderadores. Se descartan aquellos usuarios que visitan mucho en el sitio y aquellos que lo hacen muy poco.

30 Muchas otras comunidades como los MUD disponen también de sistemas de reputación numéricos.

${ }^{31}$ Véase la importancia que tiene el reconocimiento de la comunidad en la consolidación de las identidades en comunidades hackers dedicadas a piratear tarjetas de televisión digital (Mayans, 2003:136)

${ }^{32}$ Véase como en los MUD sociales, frente a los MUD de aventuras, se evitan las puntuaciones para que la comunidad sea un proyecto abierto y se evite una competencia cerrada entre sus miembros (Reid, 2003).

${ }^{33}$ Antes del pobrecito hablador el usuario anónimo era un 'pendejo sin nombre', pero la figura parecía a los editores demasiado ofensiva y la cambiaron a la de pobrecito hablador, un pseudónimo usado 
por Larra en el siglo XIX y que Parsifal, editor, propuso como un término de compromiso entre las dos actitudes de aquellos que "quieren desincentivar los anónimos" y los que "defendemos la utilidad de los anónimos".

${ }^{34}$ Véanse por ejemplo los sitios 'Bomis Babe Report' <http://babes.bomis.com/> y 'use Perl' $<$ http://use.perl.org/>, basados en Slash y en los que no se admiten comentarios anónimos.

${ }^{35}$ El caso de las normas sobre ortografía es ejemplar. Un usuario comete una falta de ortografía, otro le critica y este último reclama su derecho a una ortografía "imaginativa", por ejemplo. Un pobrecito hablador señala que está "fuera de tema" enviar un comentario corrigiendo alguna falta de ortografía. No hay ninguna norma en Barrapunto, en ninguna parte, que explicite claramente que debe cuidarse la ortografía.

${ }^{36}$ Véase en <http://barrapunto.com/faq.shtml>.

${ }^{37}$ Véase en <http://barrapunto.com/anonimos.shtml>.

${ }^{38}$ Véase en <http://barrapunto.com/moderation.shtml>.

${ }^{39}$ Puede consultarse Slashdot en <http://www.slashdot.com>.

${ }^{40}$ Sobre la organización herterárquica de Barrapunto, véase la descripción que se hace de Slashdot en Chan, (2002)

${ }^{41}$ En el caso de los MUD se aprecian diferencias técnicas entre aquellos sociales o de aventuras, con dinámicas muy diferenciadas, pero en ningún caso puede derivarse a partir del elemento técnico únicamente si un MUD es social o de aventuras (Reid, 2003:152).

${ }^{42}$ Véase las consideraciones que hace (Davis, sin fecha:1) sobre la dificultad de seleccionar la información más relevantes en comunidades como Usenet o el mismo Slashdot.

${ }^{43}$ Véase el estudio cuantitativo de Lampe sobre el mecanismo de moderación de Slashdot, el mismo que usan Barrapunto, donde se demuestra la dificultad para lograr que las contribuciones de más valor consigan más visibilidad.

${ }^{44}$ Véanse las FAQ de la moderación <http://barrapunto.com/moderation.shtml>.

${ }^{45}$ Existe una importante similitud entre la moderación y los sistemas de reputación. Ambos funcionan como mecanismos para regular las conductas individuales en comunidades cooperativas. Los dos consiguen motivar a los usuarios que contribuyen a la comunidad para mantener su reputación y consiguen disminuir la mala conducta, véase por ejemplo (Resnick, 2000; Kollock, 1999). Pero existen también notables diferencias. En Barrapunto la reputación (el karma) no es un elemento público (aunque sí pueden verse las moderaciones recibidas por un usuario), algo fundamental en los sistemas de reputación. Los usuarios no participan pensando en la reciprocidad futura (lo que se denomina un intercambio generalizado, véase Kollock, 2003: 262), como ocurre con los sistemas de reputación (Resnick, 2000: 46) sino motivados principalmente por el aumento de visibilidad de sus comentarios y por la gratificación puntual que representa una calificación positiva de sus contribuciones. Aunque evitar malas moderaciones que manchen la reputación del usuario es también un elemento importante.

${ }^{46}$ En su estudio sobre Slashdot Chan califica su organización de heterárquica, caracterizada por ser una mínima jerarquía y la heterogeneidad organizacional. 
${ }^{47}$ Al contrario de lo que ocurre en muchos otros entornos de comunidades en el ciberespacio, sean foros, chat, etc. como señala Sternberg "casi cada chat y sistema de publicación dispone de funcionalidades integradas para tratar con el mal comportamiento... los sistemas normalmente tienen algún tipo de responsable ejecutor de las normas similar al de los operadores en los chat" (Sternberg, 2000:55).

${ }^{48}$ Véanse las FAQ de la moderación <http://barrapunto.com/moderation.shtml>.

49 Véase como (Kollock, 1999) señala este como una condición deseable para los sistemas de reputación.

${ }^{50}$ Véanse las FAQ de la moderación <http://barrapunto.com/moderation.shtml>.

51 Sobre la importancia de la dimensiones de las comunidades para que en ellas resulte viable la cooperación puede verse (Kollock, Smith, 1996) donde se presenta la idea de que con el aumento de las dimensiones de la comunidad la cooperación se hace más difícil.

${ }^{52}$ Por ejemplo las formkeys, y algunos otros sistemas que evitan ataques sistemáticos, spam, etc.

${ }^{53}$ Sobre el efecto de un troll en un grupo de noticias de Usenet puede consultarse (Donath, 2003: 7378).

${ }^{54}$ Para una definición de los trolls puede consultarse (Burnet, 2000).

${ }^{55}$ Véase (Donath, 2003: )

\section{Anexo 1. Notación}

(*) Las entrevistas están citadas según el formato: (E. P. Autor, número del párrafo de donde procede la cita).

\section{Anexo 2. FAQ de Barrapunto sobre la moderación.}

Se trata de una traducción de las FAQ elaboradas para Slashdot. Pueden encontrarse en <http:/ / barrapunto.com/ moderation.shtml>:

Al principio, Slashdot era pequeño. Teníamos docenas de envíos diarios, y estaba todo bien. La relación señal/ruido era óptima. La moderación era innecesaria puesto que no había casi nadie que moderar. Era un mundo diferente. Un día empezamos a crecer, apareciendo más y más usuarios, e incrementándose el número de comentarios enviados. Conforme esto sucedía, muchos usuarios descubrieron nuevas formas de abuso. Los editores teníamos ya un mecanismo para controlarlo: borrar los comentarios basura. Pero el sistema había crecido, y sabíamos que era difícil de controlar todos los comentarios. Estábamos sobrepasados.

$[\ldots]$

Decidimos seleccionar a algunas personas para ayudarnos. Solo unos pocos. Como mucho unos 25. Estas personas tendrían la simple posibilidad de añadir o quitar puntos a los comentarios.

$[\ldots]$ 
El sistema funcionaba bastante bien, pero Slashdot continuaba creciendo, y cada vez se hacía más patente que 25 personas no eran suficientes para controlar los miles de envíos que se producían diariamente. Así que era obvio que había que hacer algo más.

$[\ldots]$

elegimos 400 más

$[\ldots]$

En este momento comencé a experimentar con maneras de restringir el poder de los moderadores para prevenir abusos. Era fácil vigilar a 25 personas, pero no tanto hacerlo con 400. Me di cuenta que algún día mi control sobre la moderación sería menor, al dar este poder a más gente.

$[\ldots]$

Entonces comencé a trabajar en la siguiente etapa: moderación en masa. Aprendí bastantes cosas al tener tantos moderadores. Tenía que limitar el poder de cada persona para prevenir que uno se dedicara a desclasificar a los demás. Y entonces vino el siguiente paso:

Hoy cualquier lector habitual de Slashdot puede ser elegido para moderar.

\section{Anexo 3. Figuras}

Figura 1. Portada de Barrapunto.

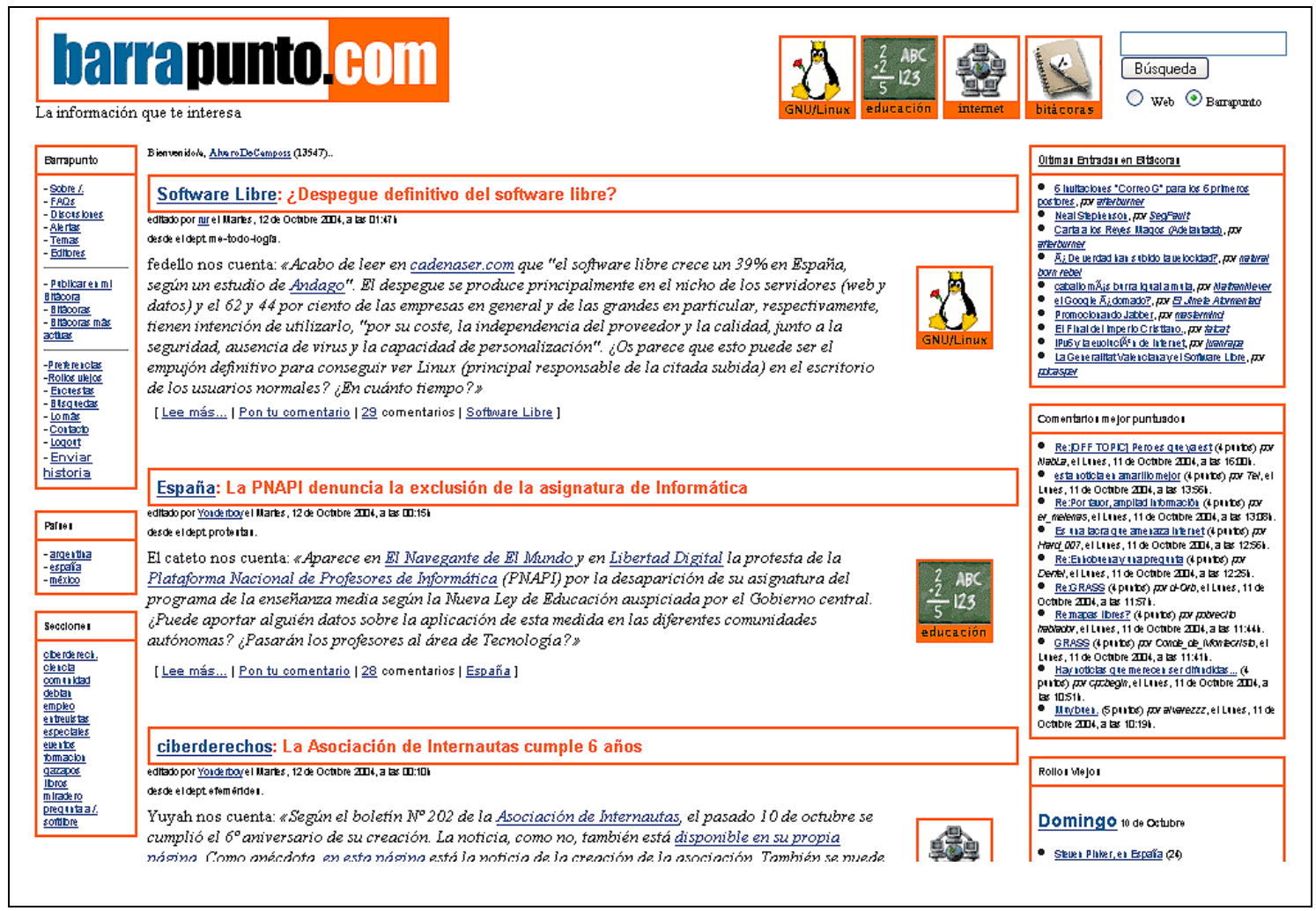


Figura 2 Fragmento de un hilo de debate en una noticia.

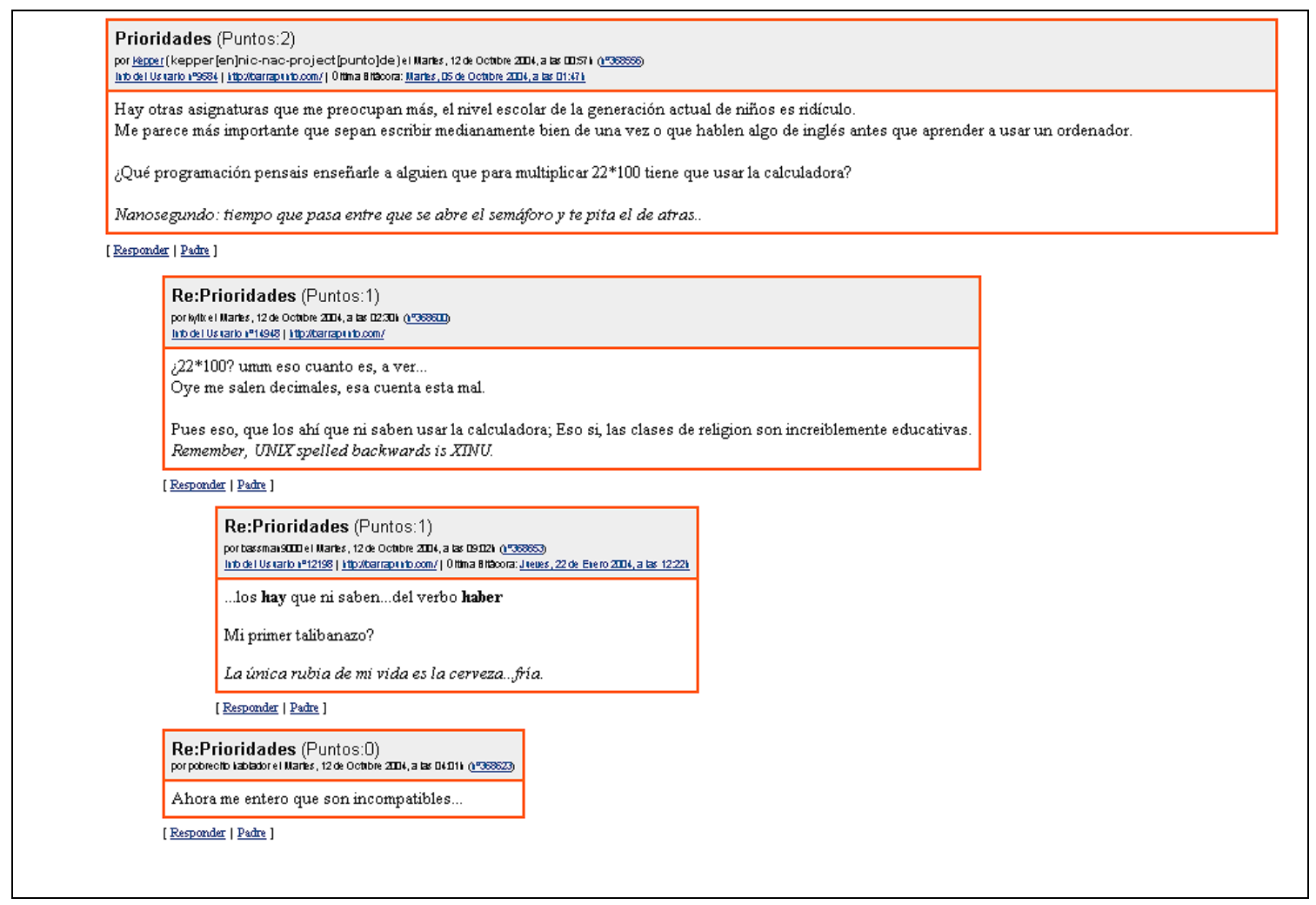

Figura 3. Historial de participación de AlvaroD eCamposs.

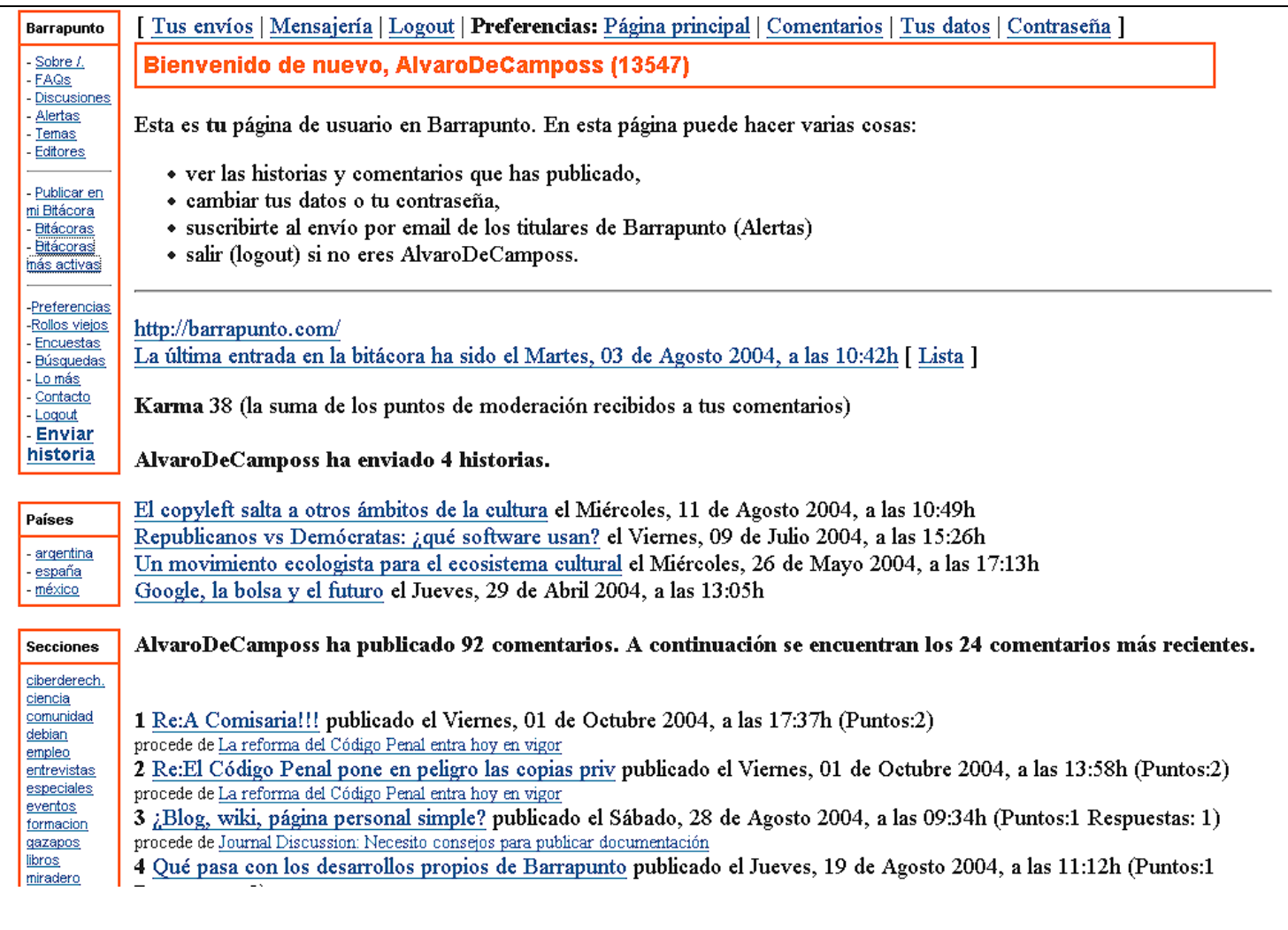


Figura 4. Mecanismo para envíos de comentarios anónimos.

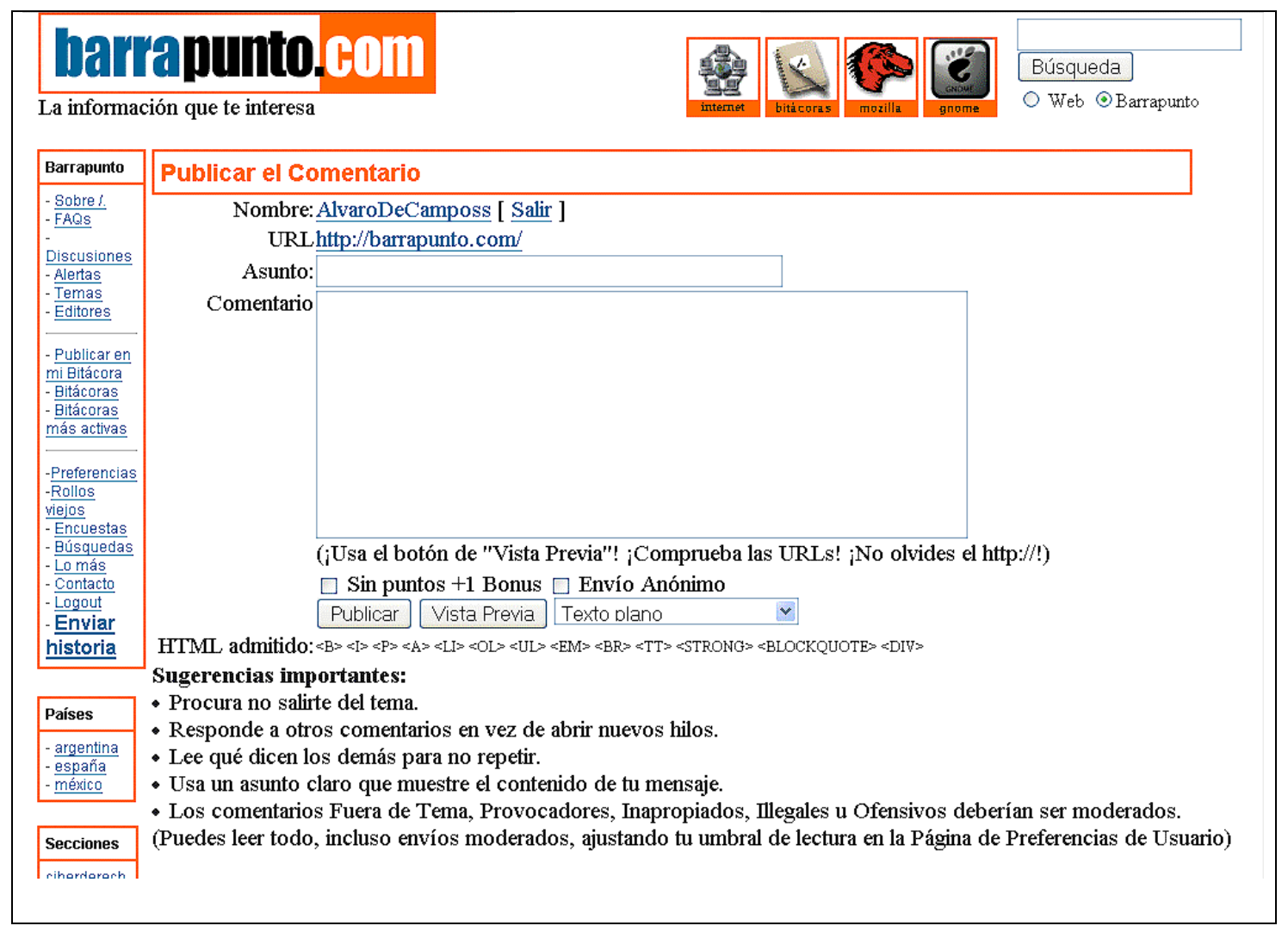

Figura 5. Categorías de la moderación

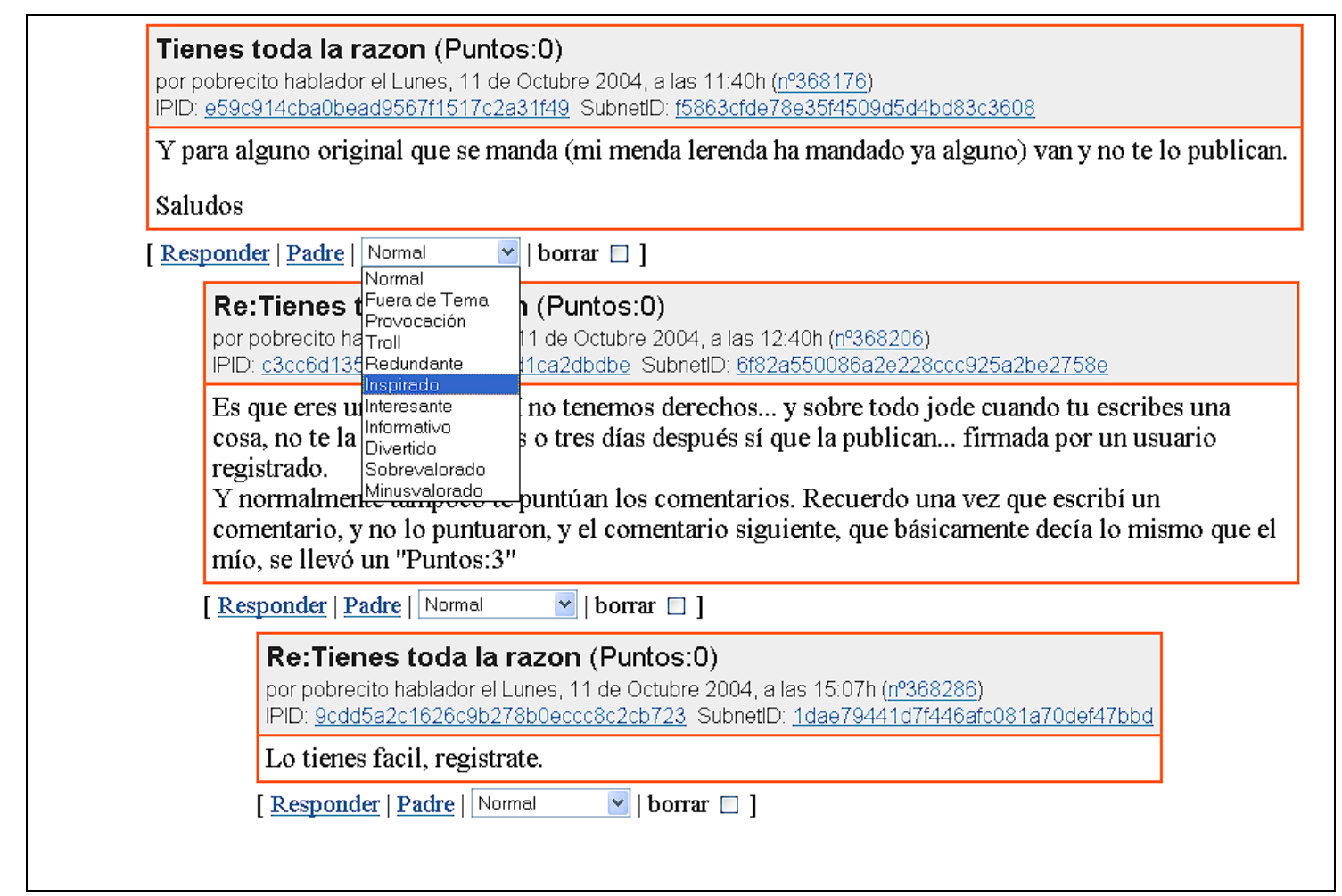




\section{Figura 6 Karma.}

\begin{tabular}{|c|c|c|}
\hline - espana & \multirow{5}{*}{ 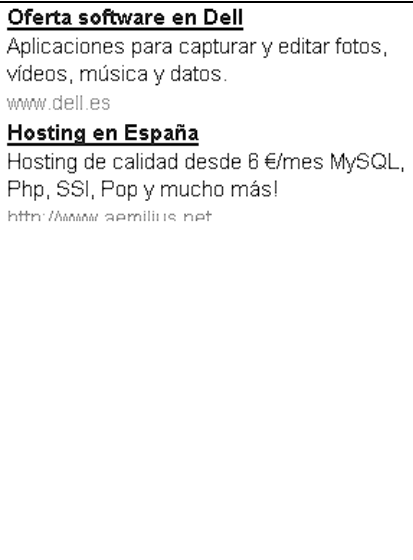 } & barrapunto. \\
\hline 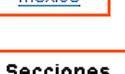 & & AlvaroDeCamposs (13547) \\
\hline \multirow{3}{*}{$\begin{array}{l}\frac{\text { ciberderech }}{\text { ciencia }} \\
\frac{\text { comunidad }}{\text { debian }} \\
\frac{\text { empleo }}{\text { entrevistas }} \\
\frac{\text { especiales }}{\text { eventos }} \\
\text { formacion } \\
\text { gazapos } \\
\text { libros } \\
\text { miradero } \\
\text { prequnta a } \\
\text { softlibre } \\
\end{array}$} & & $\begin{array}{l}\frac{\text { Mi bitácora }}{\text { Karma: } 38} \\
\text { [ Preferencias I Logout] } \\
\text { Soy AlvaroDeCampos. }\end{array}$ \\
\hline & & Enlaces relacionados \\
\hline & & $\begin{array}{l}\text { - Barrapunto } \\
\text { - camnio } \\
\text { El Periódico } \\
\text { Los dominios es no } \\
\text { triunfan en España } \\
\text { - Más sobre el terna } \\
\text { "Internet" } \\
\text { También de rvr }\end{array}$ \\
\hline
\end{tabular}

Figura 7. Ejemplo de una bitácora.

\begin{tabular}{|c|c|}
\hline Barrapunto & 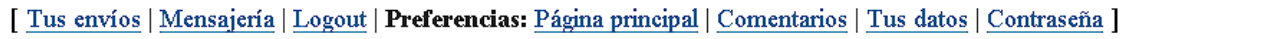 \\
\hline \multirow{3}{*}{$\begin{array}{l}\text { - Sobre } 1 . \\
\text { - FAQS } \\
\text { - Discusiones } \\
\text { - Alertas } \\
\text { - Temas } \\
\text { - Editores }\end{array}$} & [ Bitácora de AlvaroDeCamposs $\mid$ Escribir en la Bitácora $\mid$ Borrar/Editar entradas $\mid$ Top 10 $\mid$ Amigos ] \\
\hline & Bitácora de AlvaroDeCamposs (13547) XML \\
\hline & Martes, 03 Agosto 2004 \\
\hline & \multirow{6}{*}{$\begin{array}{l}\text { 10:42h - Investigando en Barrapunto: las tripas de la comunidad } \\
\text { Leo Barrapunto desde hace mucho tiempo, aunque seguro que desde hace menos que una gran parte de vosotros. Mi } \\
\text { acercamiento al principio fue como el de muchos otros, leía la portada de Barrapunto de arriba a abajo, una pasada a flor } \\
\text { de piel, sin meter la cabeza más allá de la superficie. Al cabo del tiempo, como muchos de vosotros, me registré, y } \\
\text { comencé a comentar, no demasiado, nunca he sido de los que comentan mucho. Después abrí mi bitácora (no esta de } \\
\text { AlvarodeCamposs, sino otra que mantuve con mi anterior heterónimo), y ahí si que me enganché, activamente, todos los } \\
\text { días. La mantuve durante varios meses con toda la dedicación que pude, hasta que me mudé a otra fuera de Barrapunto, } \\
\text { pero seguí manteniendo una relación fuerte con el sitio. } \\
\text { Desde hace mucho tiempo, y sé que en esto no soy el único, me ha fascinado el funcionamiento de Barrapunto. Y al } \\
\text { final me decidí a estudiarlo. He pasado los últimos cinco meses haciendo una investigación sobre Barrapunto, haciendo lo } \\
\text { que se denomina una etnografía participante. He leído las noticias, las bitácoras, he comentado... tratando de ser uno } \\
\text { más. Y he podido entrevistarme con algunos usuarios, en persona o por teléfono, a quienes agradezco sinceramente que } \\
\text { me hayan dedicado su tiempo, y he podido entrevistarme también con algunos editores, a quienes les agradezco también } \\
\text { su predisposición. La idea es comprender cómo funciona Barrapunto, cuál es la dinámica de esta 'comunidad', como } \\
\text { algunos la habéis llamado. }\end{array}$} \\
\hline $\begin{array}{l}\frac{\text { mi Bitácora }}{\text { - Bitácoras }} \\
\text { - ittácoras } \\
\text { más activas }\end{array}$ & \\
\hline $\begin{array}{l}\text {-Preferencias } \\
\text {-Rollos viejos } \\
\text { - Encuestas } \\
\text { - Búsquedas } \\
\text { - Lo más } \\
\text { - Contacto } \\
\text { - Logout }\end{array}$ & \\
\hline & \\
\hline Países & \\
\hline & \\
\hline Secciones & \multirow{5}{*}{$\begin{array}{l}\text { No voy a hacer una crítica de Barrapunto, y tampoco un panegírico, no pondré de manifiesto las posibles mejoras, si es } \\
\text { que son necesarias. En mi modesto trabajo simplemente trataré de describir con los ojos de un profano y pensando en } \\
\text { otro profano cómo funciona Barrapunto. } \\
\text { Dentro de unos meses habré escrito mi trabajo sobre Barrapunto, lo presentaré como una tesina doctoral en el Internet } \\
\text { Interdisciplinary Institute (IN3) de la Universitat Oberta de Catalunya. Después de eso lo colgaré en la Red con una } \\
\text { licencia Creative Commons, exigiendo sólo el reconocimiento y compartir igual. Es de justicia devolver una pequeña } \\
\text { contribución por mi parte. } \\
\text { Hay un aspecto metodológico importante que quiero mencionar. Barrapunto es un sitio abierto y público, con lo }\end{array}$} \\
\hline $\begin{array}{l}\frac{\text { ciberderech. }}{\text { ciencia }} \\
\text { comunidad } \\
\text { debian }\end{array}$ & \\
\hline $\begin{array}{l}\frac{\text { empleo }}{\text { entrevistas }} \\
\text { especiales }\end{array}$ & \\
\hline $\begin{array}{l}\text { eventos } \\
\text { formacion } \\
\text { gazapos }\end{array}$ & \\
\hline & \\
\hline
\end{tabular}


Figura 8. Portada de las bitácoras

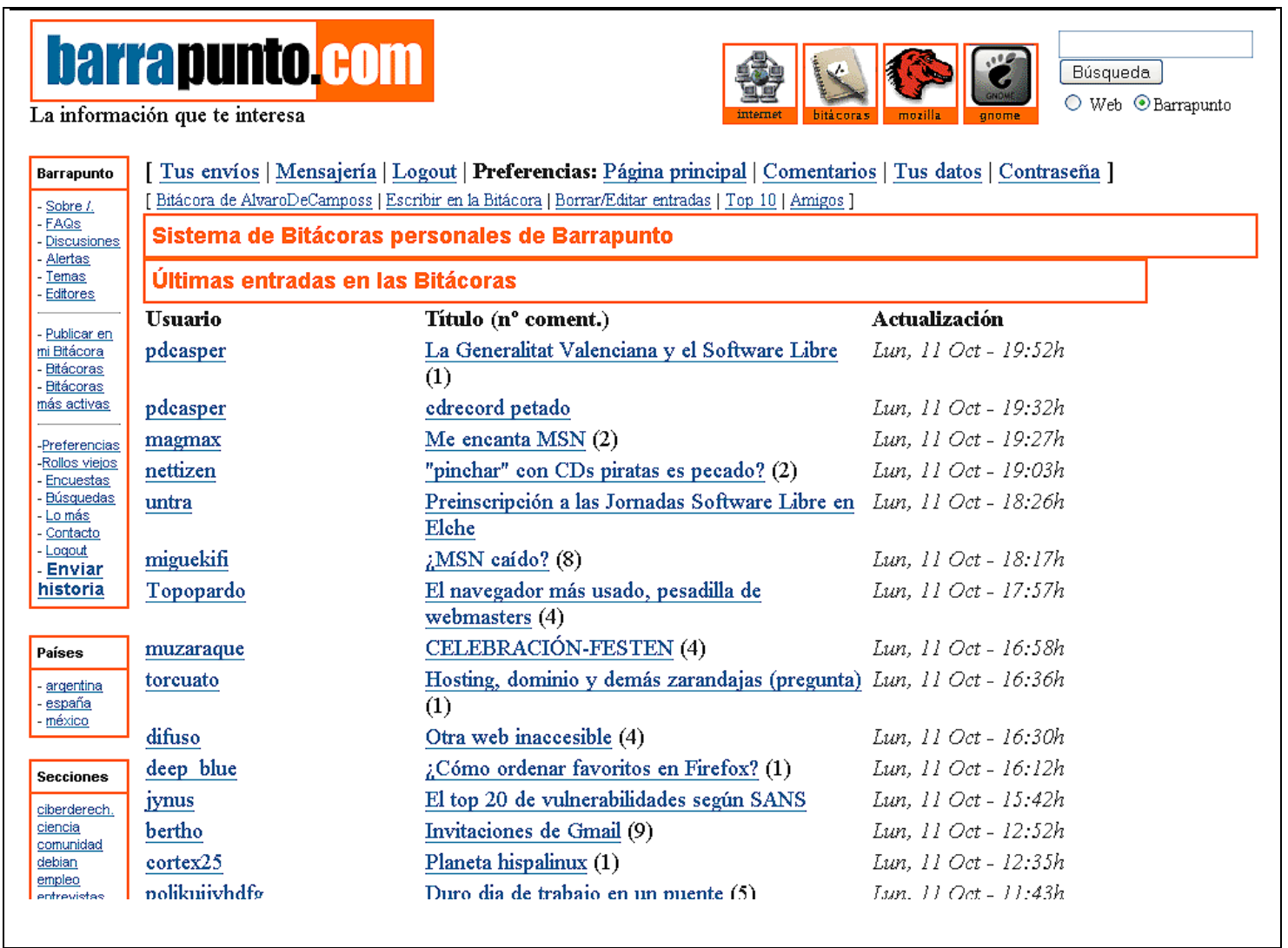

